\title{
Coastal community resilience frameworks for disaster risk management
}

\author{
Arif Almutairi $^{1} \cdot$ Monjur Mourshed $^{1}$ (D) Raed Fawzi Mohammed Ameen ${ }^{1,2}$
}

Received: 10 April 2018 / Accepted: 4 February 2020 / Published online: 17 February 2020

(c) The Author(s) 2020

\begin{abstract}
Extreme weather events due to climate change and growing economic and development activities along coastlines have resulted in increased risks from natural and human-induced disasters-affecting the safety and livelihoods of coastal communities. Assessing community resilience to disasters is, therefore, an essential step toward mitigating their current and future risks. This study provides a systematic review of coastal community resilience frameworks for disaster risk management, covering their content, structure, and assessment. Sixty-four critical resilience criteria under four dimensions are identified by analyzing the convergence and divergence of the consideration of assessment indicators in the reviewed frameworks. Existing frameworks focus mostly on 'governance and institutions,' 'infrastructure,' and 'society and the economy.' Despite significant risks, the impacts on the environment and potential risks of climate change are not prioritized. Only $22 \%$ of the frameworks consider future risks, rendering the remainder inadequate for assessing projected risks from climate change. None of the frameworks consulted the full spectrum of stakeholders (public, government, and experts) during the development process, which compromised their applicability, acceptability, and effectiveness. 56\% of the frameworks considered a single hazard type. Community resilience is inherently multi-dimensional. Therefore, the interrelationships between multiple hazards should be adequately addressed in future frameworks.
\end{abstract}

Keywords Coastal communities $\cdot$ Resilience indicators $\cdot$ Assessment framework $\cdot$ Coastal hazards $\cdot$ Disaster risk management

Arif Almutairi

Aref.t@hotmail.com

$\triangle$ Monjur Mourshed

MourshedM@cardiff.ac.uk

1 School of Engineering, Cardiff University, The Parade, Cardiff CF24 3AA, UK

2 Department of Architecture, College of Engineering, University of Karbala, Karbala, Iraq 


\section{Introduction}

Coastal areas are increasingly at risk from both natural and human-induced hazards. Assessing community resilience is an essential first step toward reducing disaster risk in a community and enhancing its resilience to natural and human-induced disasters (Burton 2015). According to Lloyd et al. (2013), fast-changing climate in the recent past and have led to a greater attention being placed on the development and implementation of adaptive administrative practices to mitigate and address the unique conditions present in coastal regions. Cooper and Boyko (2010) observe that, in ideal circumstances, coastal communities and their infrastructure would be situated at a sufficient distance from the shore to guarantee adequate protection from the threat of disasters. However, in many countries, a large proportion of the infrastructure and population is located close to the shore, rendering them vulnerable to hazardous events.

Human encroachment into narrow coastal land increases the vulnerability of communities to coastal hazards. Coastal resilience entails the development and deployment of measures to minimize harm and ensure a rapid recovery during and after a disaster, which is a promising approach to mitigating disaster risks. Ewing and Synolakis (2011) report that the coastlines of the world have, for centuries, formed the epicenters of business, commerce, transportation, and industry. The diversity of resources and opportunities positioned along these coastlines have attracted a large population, leading to urban agglomerations, ranging from sizeable towns to megacities. According to Courtney et al. (2008), Ewing and Synolakis (2011), Arbon (2014), and Chelleri et al. (2015), approximately $40 \%$ of the global population resides within $100 \mathrm{~km}$ of the coast. Furthermore, it is estimated that, due to the increasing rate of urbanization, approximately half of the global population will live in coastal communities in the future.

Spellman and Whiting (2006) and Sharifi and Yamagata (2016) note that rising sea levels and the increased occurrence of coastal storms necessitate the relocation of communities situated close to shorelines and the establishment of infrastructures further inland. However, these strategies can prove unviable when faced by an increase in population and urbanization. Often, the only viable alternative is to devise and implement measures to facilitate coastal sustainability and resilience. Arbon et al. (2016) state that one method of reducing the vulnerability of coastal communities and their infrastructure is to improve coastal resilience. In addition, Lloyd et al. (2013) and Meerow et al. (2016) define coastal resilience as the ability for both human and natural communities to resume their normal lives; i.e., 'bounce back,' following events such as coastal storms, hurricanes, and flooding, rather than simply reacting to the impact of such events. Thus, coastal communities that are better prepared and informed are more likely to rebound from climate and weather-related phenomena. Cutter et al. (2014) state that preparation can facilitate rapid recovery and also minimize the negative impact on the safety of the communities and economy. Meerow et al. (2016) consider that an evaluation of community resilience not only facilitates an indepth understanding of disasters but also assists in the formulation of informed, evidencebased strategies, capable of minimizing the impact of natural events and hasten the pace of recovery. Resilience has recently been integrated as a key element of the United Nations International Strategy for Disaster Reduction (UNISDR) (Alshehri et al. 2015).

Cimellaro et al. (2016) and Ameen et al. (2015) observe the lack of any ubiquitous model or framework for the assessment of the resilience of a community. Several researchers, including, e.g., Spellman and Whiting (2006) and Arbon (2014), emphasize the importance of focusing on community resilience, rather than vulnerability as an all-encompassing 
measure. Although there exists is no universal approach to the assessment of community resilience, researchers agree that it is characterized by several dimensions of wellbeing, including political, social, economic, and physical. There exists a number of community resilience frameworks; some of which are specific to coastal areas, e.g., the community resilience index (CRI) and coastal community resilience (CCR).

Young and Solomon (2009) argue that evidence-based practices require the application of scientific findings to prevailing circumstances, by means of the appropriate selection and critical appraisal of research findings relevant to their problem. This current study, therefore, aims to broaden the understanding of CCR assessment frameworks by critically reviewing nine selected frameworks. The specific objectives are to (a) provide a detailed overview of the frameworks; i.e., their content, structure, and development/implementation process; and (b) establish common dimensions, indicators, and sub-indicators for assessing resilience.

The development and implementation of coastal community resilience (CCR) assessment frameworks are active areas of inquiry, and approaches to which are still evolving. The significance of this study lies in the fact that in addition to taking stock of the development of CCR assessment frameworks, the findings can inform future developments. The identified factors and dimensions can act as a starting point for the involvement of stakeholders and experts in the planning and preparation processes, both within and beyond the community. This, in turn, makes it possible to address the various socioeconomic and environmental challenges faced by communities in a more effective manner. The frameworks may also contribute toward ensuring that resilience becomes a 'governable strategy,' through the development of iterative and quantifiable frameworks for resilience implementation (Larkin et al. 2015).

This rest of the article is structured as follows. The next section describes the systematic review methodology and the criteria for selecting a framework for the detailed review. The section also describes the reviewed frameworks briefly. The following section compares the selected frameworks in terms of their characteristics and structure. The results of the review are then presented and discussed next. Findings are contextualized against the literature, while conclusions are drawn in the last section.

\section{Methodology}

The systematic literature review involved the selection of research publications, which were collected, appraised, and synthesized. A rigorous and documented procedure was put in place for both the search strategy and the process of selecting the research papers. Bealt and Mansouri (2018) argue that a systematic literature review requires a scientific approach enabling researchers to conduct a detailed article search while promoting transparency and relevance and avoiding bias. Moreover, a systematic literature review enhances the knowledge base of the researcher, thus having a positive impact on both practice and policy. For the current study, relevant papers were selected using a comprehensive process of planning, searching, screening, and reporting.

As the main focus of this review concerns coastal community resilience assessment frameworks, a broad-based search strategy was implemented to develop knowledge regarding current assessment frameworks and tools applied at various coastal communities (Arbon 2014). Following an extensive scoping exercise, the key trends, themes, and gaps in the chosen papers were identified and ranked in terms of importance. The following 
databases were used to conduct the searches: ScienceDirect; IEEE Xplore; Google Scholar; and the Web of Science Core Collection. To increase the relevance of the results to the present study, the searches employed a range of different keywords related to 'frameworks,' including: (a) 'models'; (b) 'tools'; (c) 'indices'; and (d) 'toolkits,' as given in Table 1.

The search of the databases identified 429 articles. Endnote software was used to compare the papers and delete any duplicates, resulting in the exclusion of 291 documents. This left 138 items for analysis. Figure 1 indicates that the initial searches were undertaken with the objective of extracting relevant information concerning community resilience. A manual examination of the titles and abstracts of the articles was subsequently conducted to identify information on: (a) coastal community resilience; (b) coastal hazards; (c) climate-induced hazards; and (d) multi-hazards. This examination narrowed down the number of articles to forty. The final step involved a thorough reading of each article to analyze its content, focusing specifically on how the framework was designed to examine coastal community resilience as a complete system, as well as how the resilience dimensions were structured.

Most investigated frameworks were based on the needs of a specific region of the world, which resulted in each possessing varying indicators for each dimension of resilience. The current study, therefore, excluded any frameworks that considered only one aspect of community resilience. The Australian framework designed to enhance a community's resilience for health security threats (Chandra et al. 2011) and a framework that focused on earthquakes, a single form of natural disaster (Ainuddin and Routray 2012), were excluded. This step further narrowed down the number of frameworks to nine, all of which focused on multi-dimensional community resilience. These nine frameworks were then grouped under the following headings: (a) year of issue; (b) study location; (c) type of hazard; (d) type of assessment; and (e) assessment methods, as outlined in Table 2.

The nine chosen frameworks have been widely employed in their respective jurisdictions and varying contexts. Therefore, a body of knowledge exists regarding their effectiveness, applicability, and flexibility. Published and accompanying sources such as framework guidelines, policy documents, manuals, and peer-reviewed articles related to each of the frameworks were also evaluated using content analysis and an analytical framework.

A list was subsequently drawn up of the initial important and common criteria related to coastal community resilience by means of a thorough review of the criteria of each of the selected frameworks. The selected criteria were categorized into four common dimensions, and several matrices were developed, with the criteria set out in the rows and frameworks in the columns. Comparison matrices were created to ensure that all related criteria were included in the list, as well as to assess the extent of the applicability of the different frameworks across several indicators and sub-indicators within the four dimensions. Content analysis was selected as the method for all analyses discussed in this paper. All nine frameworks are introduced first in the following subsection and critiqued next.

\subsection{Selected coastal community resilience frameworks}

\subsubsection{Coastal Community Resilience (CCR1)}

CCR1 was developed in 2008 with the participation of over one hundred governmental agencies and non-governmental organizations (NGOs) in the five countries that were most affected by the 2004 tsunami, namely Thailand, Sri Lanka, Indonesia, India, and the Maldives. All contributing countries are involved in the US Indian Ocean Tsunami Warning 


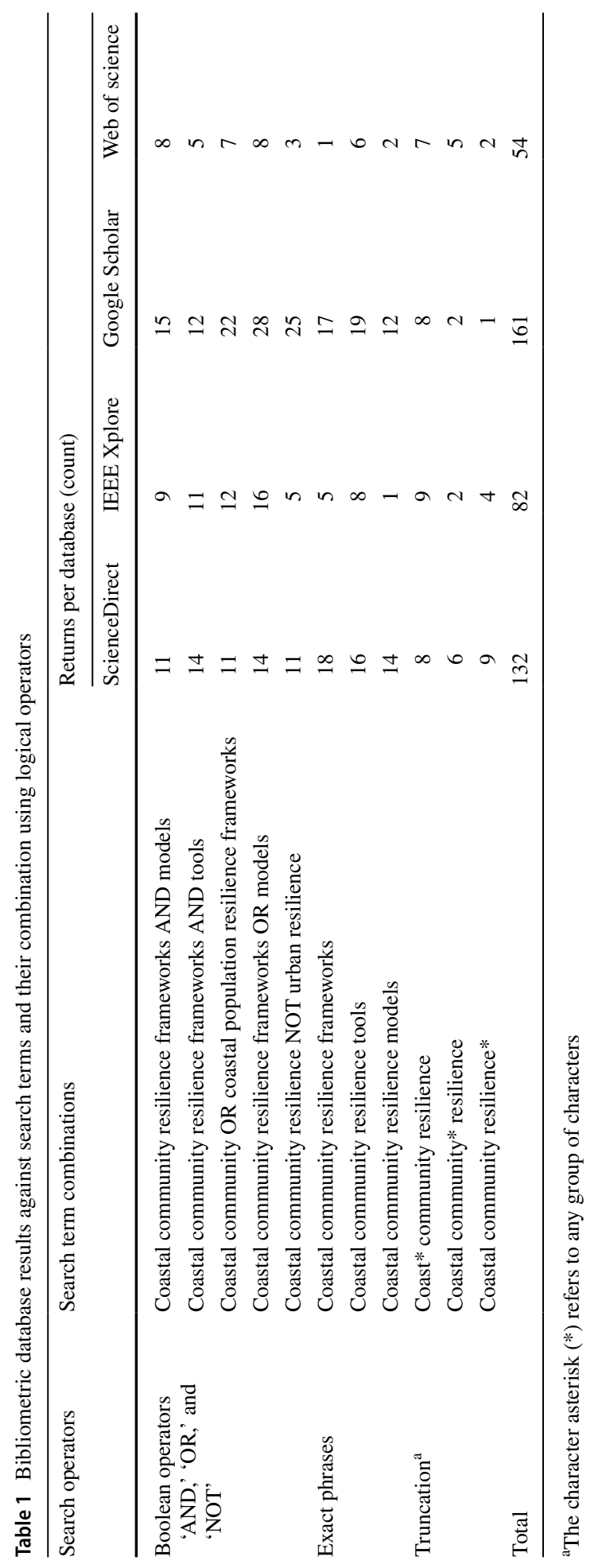




\begin{tabular}{|c|c|c|c|}
\hline $\begin{array}{c}\text { ScienceDirect } \\
2000-2017 \\
132 \text { citations }\end{array}$ & $\begin{array}{l}\text { IEEE Xplore } \\
2000-2017 \\
82 \text { citations }\end{array}$ & $\begin{array}{c}\text { Google Scholar } \\
2000-2017 \\
161 \text { citations }\end{array}$ & $\begin{array}{c}\text { Web of Science } \\
2000-2017 \\
54 \text { citations }\end{array}$ \\
\hline
\end{tabular}

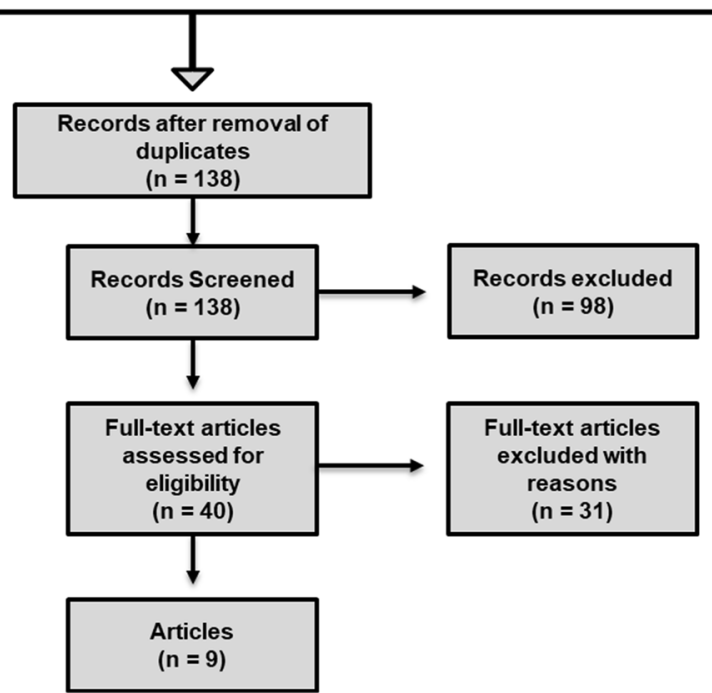

Fig. 1 Prismatic process of identification, screening, eligibility determination, and inclusion of frameworks in the study

System (US IOTWS) program. CCR1 is aimed at the assessment of coastal community resilience to natural hazards. Experience from the development of CCR1 indicates that differences exist between communities regarding the perceptions of their ability to deal with these hazards appropriately (Courtney et al. 2008).

\subsubsection{Climate Disaster Resilience Index (CDRI)}

Climate disaster resilience index (CDRI) was developed in 2009 by the Global Center for Education and Research on Human Security Engineering for Asian Megacities, Kyoto University, Japan. Its scope is limited to climate-induced disasters, such as cyclones, floods, heat waves, droughts, and heavy rainfall. CDRI was developed to measure the existing level of recovery from climate disasters within the targeted areas against an index titled climate disaster resilience index, from which the name of the framework was derived. CDRI provides knowledge and information to other local and national stakeholders, all of whom share the aim of enhancing community resilience (Shaw and Team 2009).

\subsubsection{Texas Community Disaster Resilience Index (TX-CDRI ${ }^{1}$ )}

In 2008, the TX-CDRI was developed by Texas A\&M University (TAMU), Texas A\&M University at Galveston (TAMUG), and the Houston Advanced Research Center (HARC)

\footnotetext{
${ }^{1}$ The prefixes, 'Texas' and 'TX' is our addition to the CDRI framework developed in Texas universities to differentiate between different CDRI frameworks.
} 


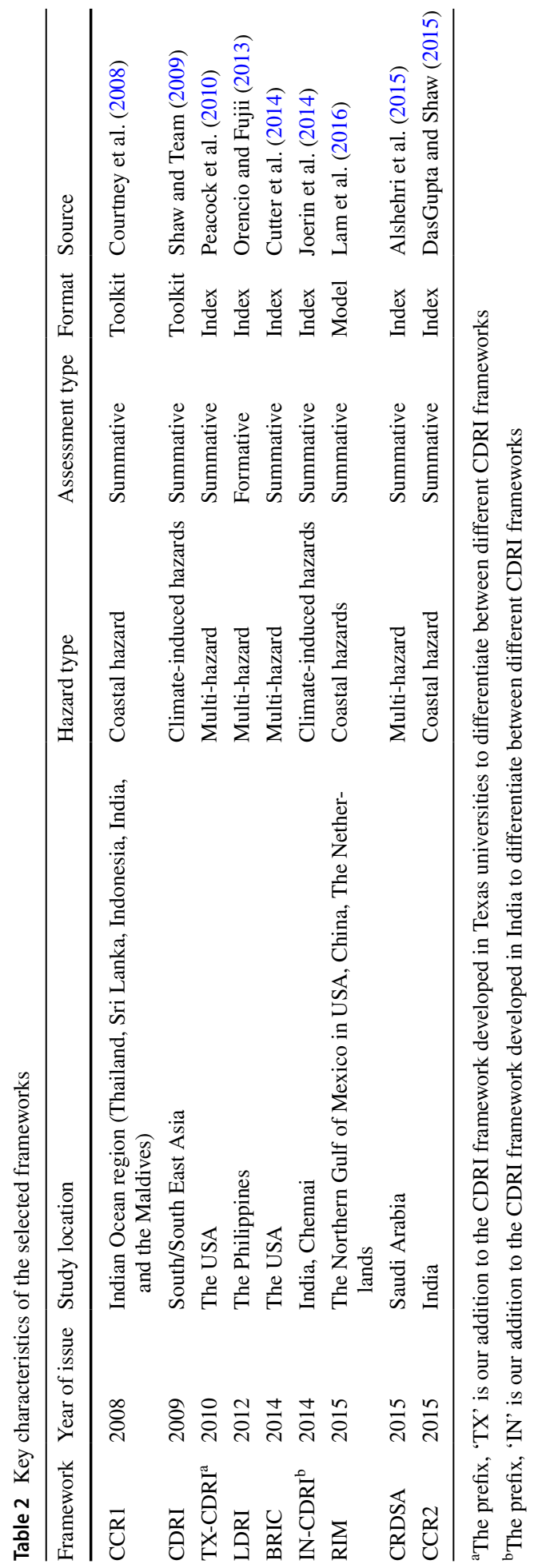


in the USA. Its aim was to focus on developing a series of indicators for community resilience that would be applicable at regional and national levels. It was developed to improve the recovery of coastal communities along the Gulf Coast and was based on data from the National Oceanic and Atmospheric Administration (NOAA). The underlying data and tools are available to the local communities, decision-makers, and stakeholders via interactive websites hosted by Texas A\&M University at Galveston (coastalatlas.tamug.edu) and Texas A\&M College Station (coastalatlas.tamu.edu) (Peacock et al. 2010).

\subsubsection{Localized Disaster Resilience Index (LDRI)}

LDRI was developed in 2012. It proposed an index for a disaster-resilient coastal community on a local level in the Philippines. The development process utilized the Delphi technique, a structured communication technique involving a panel of experts. LDRI involved twenty decision-makers in Baler, Aurora (Philippines), in identifying the criteria and elements that can be used to reduce the vulnerability of coastal communities. The identified criteria were further structured using the analytic hierarchy process (AHP) and used paired comparisons (Orencio and Fujii 2013).

\subsubsection{Baseline Resilience Indicators for Communities (BRIC)}

BRIC was developed in 2014 to measure the resilience of communities in specific areas of the USA. The framework was constructed by calculating the total scores for the composites of six sub-indices for resilience: social, economic, community capital, institutional, infrastructural, and environmental. The potential scores range from zero to six, with higher scores corresponding to greater resilience and lower ones to less resilience. BRIC provides a reference point or baseline for examining the current status of inherent resilience at the county level, which can be useful in guiding local policy decisions. Although the framework provides an overall measure of resilience, it does not, however, for every individual indicator (Cutter et al. 2014).

\subsubsection{Indian Climate Disaster Resilience Index (IN-CDRI²)}

IN-CDRI was developed in 2014 in Chennai, India, and aimed to measure, from a community perspective, a city's capability to withstand climate-related disasters. IN-CDRI focuses on a comprehensive evaluation of all sectors of a city to hasten the resilience building process in urban areas. IN-CDRI is tailored specifically to climate-related hazards such as cyclones, droughts, floods, and heat waves, which are more likely to occur in Chennai than the geophysical hazards. Engineers (experts) operating in the ten different zones of Chennai, who carry out civic works, were selected as representatives to provide responses to the IN-CDRI questionnaire. The engineers weighed the importance of each variable and parameter in terms of its influence on the overall resilience score. The IN-CDRI assessment integrates aspects related to the Hyogo Framework for Action (HFA) 2005-2015 (Joerin et al. 2014).

\footnotetext{
${ }^{2}$ The prefix, 'Indian' and 'IN' is our addition to the CDRI framework developed in India to differentiate between different CDRI frameworks.
} 


\subsubsection{Resilience Inference Measurement (RIM)}

The RIM framework was developed in 2015 to measure the resistance to coastal hazards of fifty-two counties along the Northern Gulf of Mexico in the USA. RIM uses exposure, damage, and recovery indicators to denote two relationships-vulnerability and adaptability. The framework utilizes both discriminant analysis and $k$-means clustering to derive resilience rankings. Five major types of coastal hazards were included in the RIM: coastal (including coastal flooding and storm surges), floods, hurricanes, thunderstorms, and tornadoes (Lam et al. 2016).

\subsubsection{Community Resilience Framework (CRDSA)}

In 2015, the CRDSA was developed in Saudi Arabia using a mixed-methods strategy (including quantitative and qualitative research). The CRDSA provides an assessment system, in which each criterion is weighted in order to evaluate the community's resilience in coping with future disasters. Based on a comprehensive literature search and a national survey of public perceptions of disasters in Saudi Arabia, the CRDSA was developed using the Delphi technique and AHP (Alshehri et al. 2015).

\subsubsection{Coastal Community Resilience (CCR2)}

CCR2, developed in 2015, aims to measure the resilience of a particular community to natural coastal hazards in rural areas in the Indian Sundarbans. The CCR methodology is divided into two parts. The first is concerned with the development of a series of criteria and variables that can be applied on a local level in rural coastal areas, while the second aims to assess, through a methodical application of the framework, the ability of the particular area under study to recover (DasGupta and Shaw 2015).

\section{Comparison of the coastal community resilience frameworks}

A quantitative comparison of the criteria and indicators within the nine selected frameworks can assist users and framework developers in appreciating the focus, commonality, and differences between the frameworks, and identify directions for future research and development. The assessment frameworks were compared based on key characteristics and structure.

\subsection{Key characteristics}

The key characteristics of the assessment frameworks are presented in Table 2. They have been organized into five major categories: year of issue, study location, hazard type, assessment type, and assessment methods. The findings of this comparison are discussed as follows.

\subsubsection{Timeline}

All of the selected frameworks have been developed between 2008 (CCR1) and 2015 (CCR2), thus confirming that the subject of coastal community assessment is a relatively recent development on an international level. The fact that several assessment frameworks 
were published within this relatively short period demonstrates a great deal of attention paid by the scientific community on the topic in recent years (Sharifi 2016).

\subsubsection{Location}

The selected frameworks have been implemented in regions that are vulnerable to different types of maritime disasters, such as tropical cyclones and tsunamis. As given in Table 2, three (TX-CDRI, RIM, and BRIC) of the nine selected frameworks were purposely developed in order to assess the resilience of territories in the USA (Cutter et al. 2014; Lam et al. 2016; Peacock et al. 2010). The remaining six frameworks were used to assess resilience in Asian countries. For instance, CCR1 and CCR2 were used in India, LDRI in the Philippines, IN-CDRI in China and India, CDRI in South East Asia, and CRDSA in the Kingdom of Saudi Arabia (Alshehri et al. 2015; Courtney et al. 2008; DasGupta and Shaw 2015; Joerin et al. 2014; Orencio and Fujii 2013; Shaw and Team 2009). CCR1 is a cooperative framework (Courtney et al. 2008), and several countries (Thailand, Sri Lanka, Indonesia, India, and the Maldives) participated in its development.

The frameworks have not only been developed by international organizations but also by individual researchers. However, it is important to note that there remains a lack of assessment frameworks that have been developed by local authorities and organizations in developing countries. The frameworks that have been developed by non-local stakeholders may fail to appropriately reflect the local needs and conditions of the countries or regions.

\subsubsection{Hazard type}

Assessing community resilience is recognized as a fundamental step toward reducing disaster hazards and being better prepared to withstand and adapt to a broad array of natural and human-induced disasters that threaten coastal communities. Therefore, all of the selected frameworks have been used to assess the resilience of different communities across the globe to a large percentage of the different types of hazards. Hence, there exist significant differences between the selected frameworks. For instance, as given in Table 2, CCR1, RIM, and CCR2 are designed to address coastal natural hazards only (Lam et al. 2016), while TX-CDRI, LDRI, BRIC, and CRDSA are focused on multi-hazards, and CDRI and IN-CDRI address climate-induced hazards. Overall, it can be said that CCR1, CDRI, TXCDRI, IN-CDRI, LDRI, BRIC, RIM, CRDSA, and CCR2 are broad based and address most of the risks posed by the hazards occurring in multiple domains.

\subsubsection{Assessment type: formative versus summative}

Additionally, the assessment frameworks can be classified as either formative or summative (Sharifi 2016). Summative frameworks measure the effectiveness of resilience interventions following the occurrence of disasters, while formative frameworks entail prior assessments and the continuous evaluation of resilience measures from their inception. Formative assessments typically contain evaluations based on forecasts rather than actual results. Moreover, they cover issues related to the constant monitoring of the conditions that started during the early steps of the planning process. In other words, they rely on methodologies that are process based and have the aim of increasing adaptive capability by conducting an incremental enhancement of the conditions (Dolin et al. 2017). The benefit of formative assessments is that they enhance the opportunities for learning. Taking 
their iterative characteristics into consideration, this type of evaluation is appropriate for acknowledging dynamic challenges as well as preparing for future uncertainties.

Unlike formative assessments, summative assessments are carried out based on the actual findings of the effectiveness of the measures rather than the forecasts. Thus, summative assessments are perceived as an outcome-based assessment that assists communities in their understanding of their current stance on issues related to resilience. Furthermore, summative assessments use evidence required to formulate decision making about the importance of altering strategies of intervention. In this research. CCR1, CDRI, TX-CDRI, IN-CDRI, BRIC, RIM, CRDSA, and CCR2 can be classified as summative frameworks, while LDRI is the only formative framework that has been selected for this study. According to Cohen et al. (2016), formative frameworks, such as LDRI, are iterative. Thus, they are a suitable way of accounting for future uncertainty while at the same time addressing the dynamic present in different dimensions. Furthermore, this type of framework provides opportunities for in-depth learning. According to Norris et al. (2008), formative frameworks, such as LDRI, are vital for the assessment of community resilience against baseline conditions. This is essential for determining how communities change over time with regard to their vulnerability to hazards. As such, formative frameworks may be compared to longitudinal studies that assess changes over time to make credible inferences. Conversely, summative frameworks, which form $90 \%$ of the selected tools in this review, are outcome based. In this regard, they help communities to ascertain their standpoints concerning resilience. Sharifi (2016) notes that summative frameworks produce the evidence required for making important decisions concerning the changes needed to realign the resilience measures so that the interventions are more adaptive.

\subsubsection{Assessment methods}

The selected frameworks draw upon both quantitative and qualitative methods. According to Sharifi (2016), a mixed-methods approach is appropriate when data availability is problematic. Given that resilience is a value-laden concept that is influenced by attitudes and perceptions, this methodology enables the collection of ideas from community stakeholders regarding their needs in order to address concerns about the subjectivity of the assessment process.

The resilience assessment approach can be divided into four main formats: models, scorecards, toolkits, and indices (Cutter 2016).

- Models are used to reduce the complexity of the relationship between the risk and resilience factors, as well as to overcome any uncertainties or limitations related to predicting future events and their consequences. In this approach, past data on disasters are input into mathematical algorithms and scenario analyses in order to approximate future conditions (Cutter 2016).

- Scorecards allow us to obtain values for performance and assess these against each criterion within the resilience assessment framework. The values often take the form of answers to questions, calculated statistical values, or judgments/perceptions (Sharifi 2016). When using judgments in assessments, scaled questions with Likert scales are used to quantify qualitative feedback.

- Toolkits establish procedures for assessing resilience using one or more of the aforementioned methods (Cutter 2016). Toolkits not only provide guidance on how to conduct assessments but also outline mechanisms for identifying the assessment criteria, 
collecting the required data, assigning weights, conducting assessments, suggesting interventions, and monitoring action plans.

- Indices rely on quantitative data, often using weighted averages or sums of scores obtained for all criteria in the assessment tool in order to get an aggregate index value (Cutter 2016). Indices are often standardized for comparison purposes, or weights are assigned to them based on contextual and temporal factors (Table 2), using methods such as the analytic hierarchy process (AHP) (Alshehri et al. 2015). Index values make it possible to assign an overall performance rating to community resilience.

As given in Table 2, most of the selected frameworks are organized in the format of indices and toolkits, and only one (RIM) is organized in a model format.

\subsection{Framework structure}

Despite the fact that a range of coastal community resilience frameworks has been developed over time in order to fulfill the same objective, these vary significantly in terms of their structure, potential, and application (Courtney et al. 2008). The nine selected frameworks have been chosen because of their similarity with regard to their organization, components, and procedures to ensure that the objectives of the review are met. Table 3 demonstrates the general structure of the tools. This structure comprises three levelsdimensions, indicators, and sub-indicators, which are discussed in the following sections.

\subsubsection{Dimensions}

In all of the chosen frameworks, four interrelated dimensions are covered: environmental and climate change, social and economic, infrastructure, and governance and institution, with varying degrees of emphasis on community resilience issues. This is based on local circumstances and reflects the nature of the indicators mentioned in each framework.

Resilience in terms of the environmental and climate change dimension can be roughly linked to a coastal area's exposure to specific coastal hazards (i.e., rising sea levels). Within each community, there is a different level of exposure to natural hazards. Equally, the distribution of risks to hazards is not uniform across different communities (Lam et al. 2016). This means that the level of natural/environmental resilience linked to each area will vary. Additionally, the environmental safeguarding action for each indicator has been introduced in order to incorporate specific actions that may be carried out to mitigate the threats arising from climate change. These actions are often adapted in accordance with the existing risk response mechanisms of local governments. While these factors may, at times, be considered to be negligible, they also have the potential to become highly detrimental to a society and its economy during periods of catastrophe.

In all nine frameworks, the importance of the social and economic resilience dimension has been widely emphasized. In coastal communities, social and economic resilience refers to the ability of a community to survive on limited natural resources when they are typically highly dependent on such resources (DasGupta and Shaw 2015). Table 3 illustrates that the various indicators and sub-indicators that can be categorized under 'social and economic resilience' include demographics, livelihood, awareness, training, culture, employment, safety, and security.

In terms of the infrastructure resilience dimension, utilities, communication, and public services are all essential for reducing the impact of disasters (McDaniels et al. 2008). 
Table 3 General structure of the nine reviewed frameworks

\begin{tabular}{|c|c|c|c|c|}
\hline $\begin{array}{l}\text { Frame- } \\
\text { work }\end{array}$ & Dimension & Indicator & $\begin{array}{l}\text { Num- } \\
\text { ber of } \\
\text { sub- } \\
\text { indi- } \\
\text { cator }\end{array}$ & $\begin{array}{l}\text { Weight } \\
(\%)\end{array}$ \\
\hline \multirow[t]{9}{*}{ CCR1 } & \multirow{9}{*}{$\begin{array}{l}\text { 1. Policy } \\
\text { and plan- } \\
\text { ning } \\
\text { 2. Physi- } \\
\text { cal and } \\
\text { environ- } \\
\text { mental } \\
\text { 3. Social } \\
\text { and } \\
\text { cultural } \\
\text { 4. Techni- } \\
\text { cal and } \\
\text { financial }\end{array}$} & 1. Governance & 10 & \\
\hline & & 2. Society and economy & 6 & \\
\hline & & 3. Coastal resource management & 6 & \\
\hline & & 4. Land use and structural design & 7 & \\
\hline & & 5. Risk knowledge & 4 & \\
\hline & & 6. Warning and evacuation & 7 & \\
\hline & & 7. Emergency response & 4 & \\
\hline & & 8. Disaster recovery & 10 & \\
\hline & & Subtotal & 54 & N/A \\
\hline \multirow[t]{28}{*}{ CDRI } & \multirow[t]{9}{*}{ 1. Physical } & 1. Electricity & & \\
\hline & & 2. Water supply & & \\
\hline & & 3. Sanitation & & \\
\hline & & 4. Solid waste disposal & & \\
\hline & & 5. Internal road network & & \\
\hline & & 6. Housing and land use & & \\
\hline & & 7. Community assets & & \\
\hline & & 8. Warning system and evacuation & & \\
\hline & & Subtotal & N/A & N/A \\
\hline & \multirow[t]{4}{*}{ 2. Social } & 1. Health status & & \\
\hline & & 2. Education and awareness & & \\
\hline & & 3. Social capital & & \\
\hline & & Subtotal & N/A & N/A \\
\hline & \multirow{7}{*}{$\begin{array}{l}\text { 3. Eco- } \\
\text { nomic }\end{array}$} & 1. Income & & \\
\hline & & 2. Employment & & \\
\hline & & 3. Households' assets & & \\
\hline & & 4. Access to financial services & & \\
\hline & & 5. Savings and insurance & & \\
\hline & & 6. Budget and subsidy & & \\
\hline & & Subtotal & N/A & N/A \\
\hline & \multirow{5}{*}{$\begin{array}{l}\text { 4. Institu- } \\
\text { tional }\end{array}$} & 1. Internal institutions and development plan & & \\
\hline & & 2. Effectiveness of internal institutions & & \\
\hline & & 3. External institutions and networks & & \\
\hline & & 4. Institutional collaboration and coordination & & \\
\hline & & Subtotal & N/A & N/A \\
\hline & \multirow[t]{3}{*}{ 5. Natural } & 1. Hazard intensity & & \\
\hline & & 2. Hazard frequency & & \\
\hline & & Subtotal & N/A & N/A \\
\hline
\end{tabular}


Table 3 (Continued)

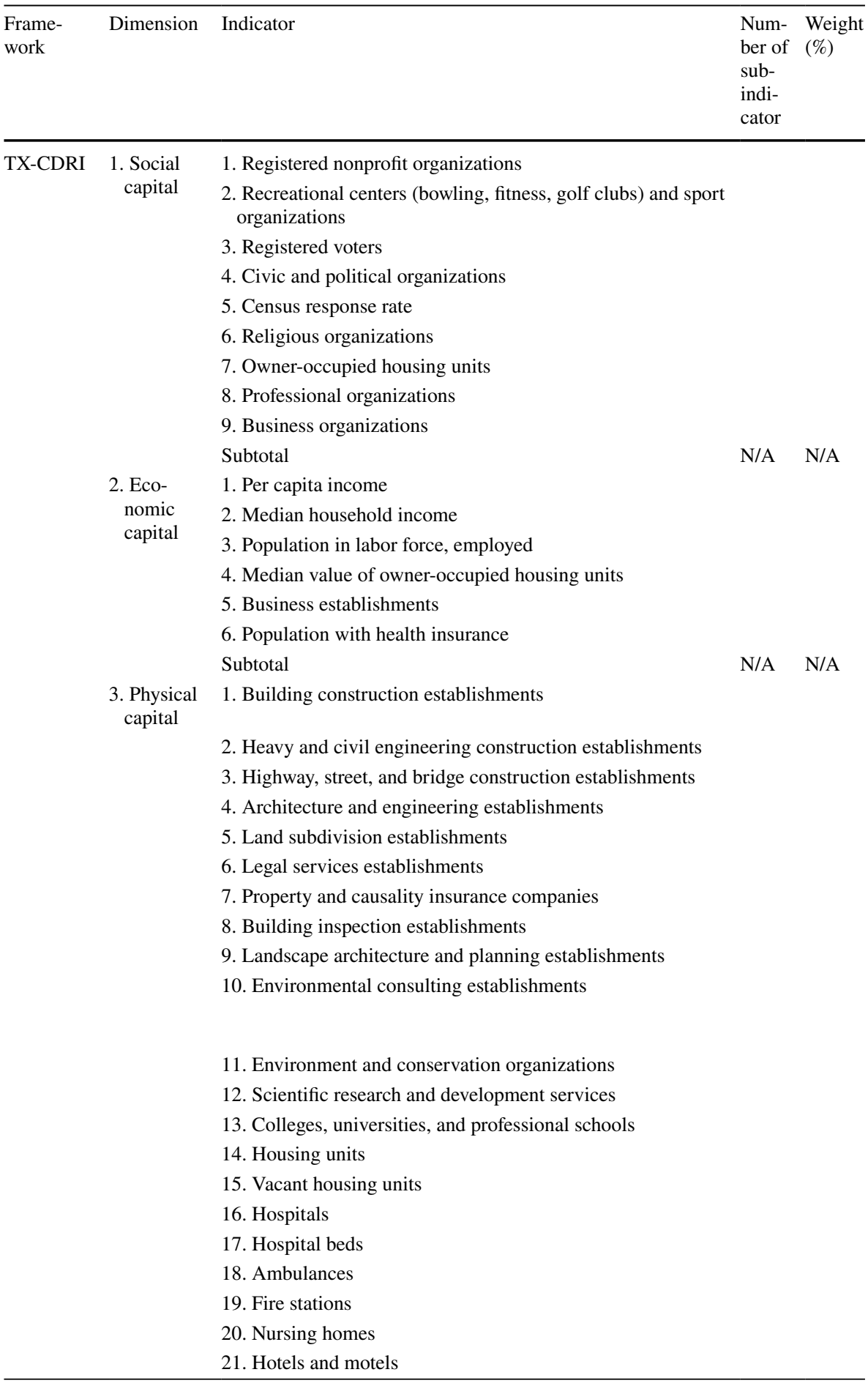


Table 3 (Continued)

\begin{tabular}{llll}
\hline $\begin{array}{l}\text { Frame- } \\
\text { work }\end{array}$ & Dimension & Indicator & Num- Weight \\
& & ber of $(\%)$ \\
& sub- \\
& indi- \\
& & cator \\
\hline
\end{tabular}

22. Occupied housing units with vehicle available

23. Special needs transportation services

24. School and employee buses

25. Owner-occupied housing units with telephone service

26. Newspaper publishers

27. Radio stations

28. Television broadcasting

29. Internet service providers

30. Temporary shelters

31. Housing

32. Community food service facilities

33. Schools

34. Licensed childcare facilities

35. Utility systems construction establishments

Subtotal

N/A N/A

4. Human 1. Population with more than high school education

capital

2. Physicians

3. Population employed in health care support

4. Population employed in building construction establishments

5. Population employed in heavy and civil engineering constructions

6. Population employed in architecture and engineering establishments

7. Population employed in environmental consulting services

8. Population employed in environment and conservation organizations

9. Population employed in land subdivision services

10. Population employed in building inspection services

11. Population employed in landscape architecture and planning establishments

12. Population employed in property and causality insurance companies

13. Population employed in highway, street, and bridge construction

14. Population employed in legal services

15. Population covered by comprehensive plan

16. Population covered by zoning regulations

17. Population covered by building codes

18. Population covered by FEMA approved mitigation plan

19. Community rating system (CRS) score 
Table 3 (Continued)

\begin{tabular}{|c|c|c|c|}
\hline $\begin{array}{l}\text { Frame- } \\
\text { work }\end{array}$ & Dimension & Indicator & $\begin{array}{l}\text { Num- Weight } \\
\text { ber of }(\%) \\
\text { sub- } \\
\text { indi- } \\
\text { cator }\end{array}$ \\
\hline
\end{tabular}

20. Population employed as firefighting, prevention, or law enforcement workers

21. Population employed in scientific research and development services

22. Population employed in colleges, universities, and professional schools

23. Population who speak English language very well

24. Population employed in special need transportation services

25. Population employed in community and social services

Subtotal

N/A N/A

LDRI

1. Environ-

1. Understanding of functioning environment and ecosystems

7.42

mental

2. Environmental practices that reduce hazard risk

7.24

and

natural

resource

manage-

3. Preservation of biodiversity for equitable distribution system

ment

4. Application of indigenous knowledge and technologies

3.89

5. Access to community-managed common property

Subtotal

N/A $\quad 25.10$

2. Sustain- 1. High level of local economic and employment stability

2. Equitable distribution of wealth and livelihood in com-

3. Livelihood diversification in rural areas

4. Fewer people engaged in unsafe livelihood

5. Adoption of hazard-resistant agriculture

6. Small enterprises with protection and business continuity/ recovery plans

7. Local market and trade links protected from hazards

Subtotal

N/A $\quad 35.78$

3. Social 1. Social support and network systems on DRR activities

8.57

protection

2. Cooperation with local community for DRR activities

3. Community access to basic social services

3.30

4. Established social information and communication channels

5. Collective knowledge and experience of management of previous events

Subtotal

4. Planning 1. Community decision making takes on land use and hazards

2. Local disaster plans feed into local development and land use planning

3. Local community participates in all stages of DRR planning 
Table 3 (Continued)

\begin{tabular}{|c|c|c|c|c|}
\hline $\begin{array}{l}\text { Frame- } \\
\text { work }\end{array}$ & Dimension & Indicator & $\begin{array}{l}\text { Num- } \\
\text { ber of } \\
\text { sub- } \\
\text { indi- } \\
\text { cator }\end{array}$ & $\begin{array}{l}\text { Weight } \\
(\%)\end{array}$ \\
\hline \multirow[t]{4}{*}{ BRIC } & $\begin{array}{l}\text { 2. Eco- } \\
\text { nomic }\end{array}$ & $\begin{array}{l}\text { 1. Educational attainment equality } \\
\text { 2. Pre-retirement age } \\
\text { 3. Transportation } \\
\text { 4. Communication capacity } \\
\text { 5. English language competency } \\
\text { 6. Non-special needs } \\
\text { 7. Health insurance } \\
\text { 8. Mental health support } \\
\text { 9. Food provisioning capacity } \\
\text { 10. Physician access } \\
\text { Subtotal } \\
\text { 1. Home ownership } \\
\text { 2. Employment rate } \\
\text { 3. Race/ethnicity income equality } \\
\text { 4. Non-dependence on primary/tourism sectors } \\
\text { 5. Gender income equality } \\
\text { 6. Business size } \\
\text { 7. Large retail-regional/national geographic distribution } \\
\text { 8. Federal employment }\end{array}$ & N/A & N/A \\
\hline & $\begin{array}{l}\text { 3. Com- } \\
\text { munity } \\
\text { capital }\end{array}$ & $\begin{array}{l}\text { Subtotal } \\
\text { 1. Place attachment—not recent immigrants } \\
\text { 2. Place attachment—native born residents } \\
\text { 3. Political engagement } \\
\text { 4. Social capital—religious organizations } \\
\text { 5. Social capital—civic organizations } \\
\text { 6. Social capital—disaster volunteerism } \\
\text { 7. Citizen disaster preparedness and response skills }\end{array}$ & N/A & N/A \\
\hline & $\begin{array}{l}\text { 4. Institu- } \\
\text { tional }\end{array}$ & $\begin{array}{l}\text { Subtotal } \\
\text { 1. Mitigation spending } \\
\text { 2. Flood insurance coverage } \\
\text { 3. Jurisdictional coordination } \\
\text { 4. Disaster aid experience } \\
\text { 5. Local disaster training } \\
\text { 6. Performance regimes-state capital } \\
\text { 7. Performance regimes-nearest metro area } \\
\text { 8. Population stability } \\
\text { 9. Nuclear plant accident planning } \\
\text { 10. Crop insurance coverage }\end{array}$ & N/A & N/A \\
\hline & & Subtotal & N/A & N/A \\
\hline
\end{tabular}


Table 3 (Continued)

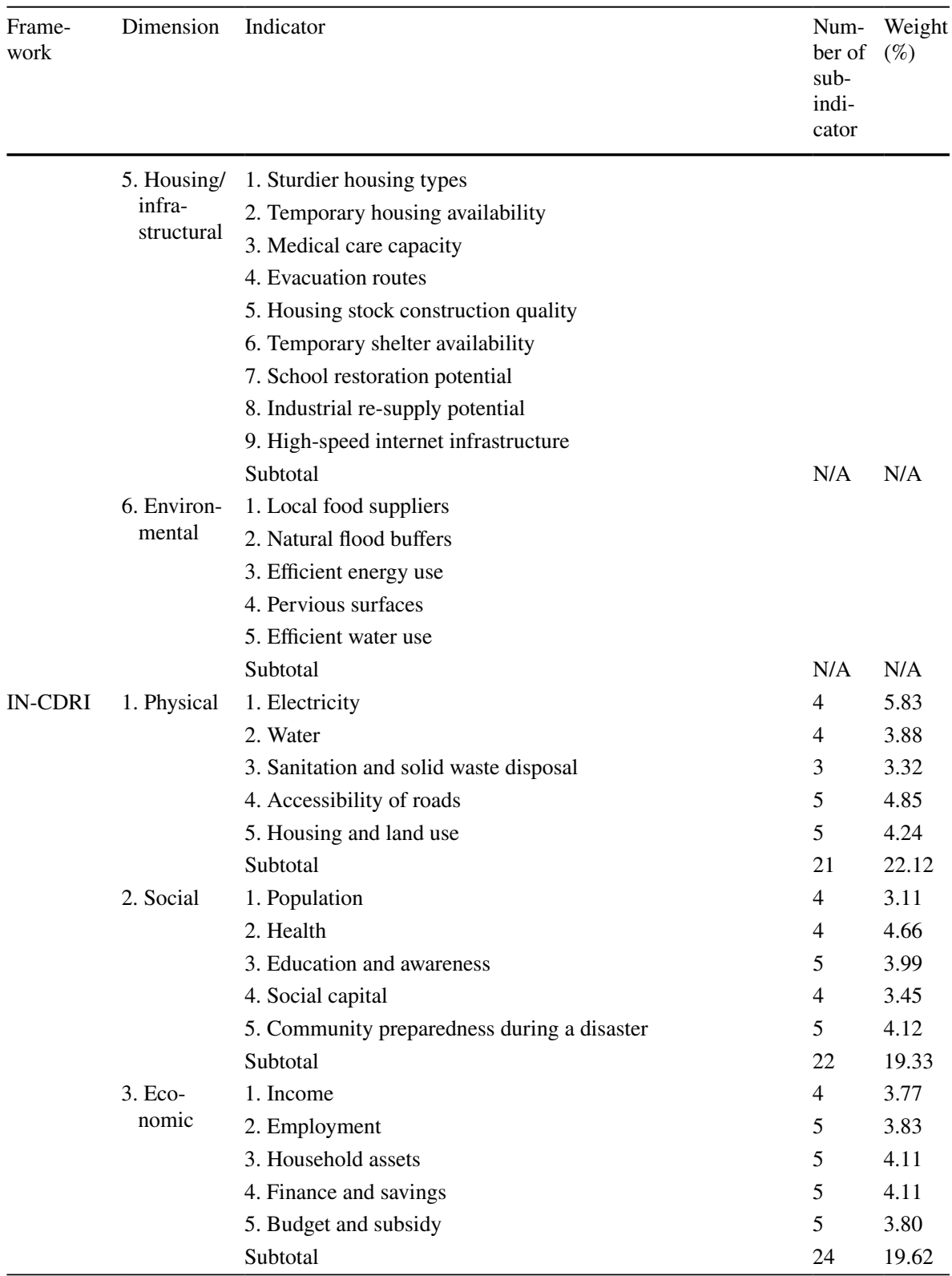


Table 3 (Continued)

\begin{tabular}{|c|c|c|c|c|}
\hline $\begin{array}{l}\text { Frame- } \\
\text { work }\end{array}$ & Dimension & Indicator & $\begin{array}{l}\text { Num- } \\
\text { ber of } \\
\text { sub- } \\
\text { indi- } \\
\text { cator }\end{array}$ & $\begin{array}{l}\text { Weight } \\
(\%)\end{array}$ \\
\hline & $\begin{array}{l}\text { 4. Institu- } \\
\text { tional }\end{array}$ & $\begin{array}{l}\text { 1. Mainstreaming of disaster risk reduction and climate- } \\
\text { change adaptation }\end{array}$ & 3 & 4.13 \\
\hline & & 2. Effectiveness of a zone's crisis management framework & 4 & 4.62 \\
\hline & & 3. Knowledge dissemination and management & 5 & 3.88 \\
\hline & & $\begin{array}{l}\text { 4. Institutional collaboration with other organizations and } \\
\text { stakeholders, during a disaster }\end{array}$ & 4 & 4.90 \\
\hline & & 5. Good governance & 4 & 4.36 \\
\hline & & Subtotal & 20 & 21.89 \\
\hline & 5. Natural & 1. Intensity/severity of natural hazards & 5 & 3.84 \\
\hline & & 2. Frequency of natural hazards & 4 & 2.98 \\
\hline & & 3. Ecosystem services & 5 & 3.17 \\
\hline & & 4. Land use in natural terms & 5 & 3.27 \\
\hline & & 5. Environmental policies & 5 & 3.77 \\
\hline & & Subtotal & 24 & 17.03 \\
\hline \multirow[t]{10}{*}{ RIM } & $\begin{array}{l}\text { 1. Demo- } \\
\text { graphic }\end{array}$ & $\begin{array}{l}\text { 1. Percent African American } \\
\text { 2. Percent Hispanic } \\
\text { 3. Percent under } 5 \text { years old } \\
\text { 4. Percent over } 65 \text { years old } \\
\text { 5. Average number of people per household }\end{array}$ & & \\
\hline & & Subtotal & N/A & N/A \\
\hline & 2. Social & $\begin{array}{l}\text { 1. Percent of the population over } 25 \text { with no high school } \\
\text { diploma } \\
\text { 2. Percent of the workforce that is female } \\
\text { 3. Percent female-headed households } \\
\text { 4. Percent of homes that are mobile homes } \\
\text { 5. Percent of the population that rents } \\
\text { 6. Number of houses per square mile }\end{array}$ & & \\
\hline & & Subtotal & N/A & N/A \\
\hline & $\begin{array}{l}\text { 3. Eco- } \\
\text { nomic }\end{array}$ & $\begin{array}{l}\text { 1. Percent of the population living below poverty } \\
\text { 2. Percent of the workforce that is employed } \\
\text { 3. Median value of owner-occupied housing } \\
\text { 4. Median rent } \\
\text { 5. Percent rural farm population }\end{array}$ & & \\
\hline & & Subtotal & N/A & N/A \\
\hline & $\begin{array}{l}\text { 4. Govern- } \\
\text { ment }\end{array}$ & $\begin{array}{l}\text { 1. Local government finance, revenue per capita } \\
\text { 2. Local government finance general expenditure per capita } \\
\text { 3. Percent of the population that voted in } 2000 \text { presidential } \\
\text { election } \\
\text { 4. Local government finance expenditure on education }\end{array}$ & & \\
\hline & & Subtotal & N/A & N/A \\
\hline & 5. Environ- & 1. Mean elevation of the county & & \\
\hline & & Subtotal & N/A & N/A \\
\hline
\end{tabular}


Table 3 (Continued)

\begin{tabular}{|c|c|c|}
\hline $\begin{array}{l}\text { Frame- } \\
\text { work }\end{array}$ & Dimension Indicator & $\begin{array}{ll}\text { Num- Weight } \\
\text { ber of }(\%) \\
\text { sub- } \\
\text { indi- } \\
\text { cator }\end{array}$ \\
\hline
\end{tabular}

6. Health 1. 5-year average infant mortality per 10,000 births

2. 3-year average chronic illness deaths per 10,000 individuals

3. Disabled and nonworking labor forces per 10,000 individuals

4. 3-year total low-birth-weight babies per 10,000 live births

5. Households with no fuel used per 10,000 house units

6. Households with no plumbing per 10,000 house units

7. Non-federal active medical doctors per 10,000 individuals

Subtotal

N/A N/A

CRDSA 1. Health

1. Access to clean water and adequate sanitation

1.91

and well-

2. Food security

1.89

being

3. Availability of trained health workers

1.8

4. Medical resources such as the availability of hospital beds

5. Infection control

6. Access to health assistance

1.76

7. Hygiene

1.76

8. Immunization programs

1.75

9. Effective biosecurity and biosafety systems

10. Disease surveillance

1.74

11. Family health education and training programs

12. Identification/definition of special needs

13. Access to mental health care and psychological support programs

14. Medical intelligence gathering

2. Govern- 1 . Disaster plans and policies including mitigation and evacuation emergency management plans

2. Unity of the leadership after the disaster

3. The application of standards and regulations regarding buildings and infrastructure

4. Shared information (transparency)

5. Considering scientific analysis of risk assessment

6. Integration with development policies and planning

7. Institutional collaboration and coordination

8. Clear partnership modalities defined and cooperation between concerned entities including private sector

9. Participation of community members (volunteerism) including women and children

10. Integrating populations with special needs into emergency planning and exercises

11. International collaboration and coordination framework 
Table 3 (Continued)

\begin{tabular}{|c|c|c|c|c|}
\hline $\begin{array}{l}\text { Frame- } \\
\text { work }\end{array}$ & Dimension & Indicator & $\begin{array}{l}\text { Num- } \\
\text { ber of } \\
\text { sub- } \\
\text { indi- } \\
\text { cator }\end{array}$ & $\begin{array}{l}\text { Weight } \\
(\%)\end{array}$ \\
\hline & \multirow{11}{*}{$\begin{array}{l}\text { 3. Physi- } \\
\text { cal and } \\
\text { environ- } \\
\text { mental }\end{array}$} & 1. Lessons learnt from previous disasters & & 1.9 \\
\hline & & $\begin{array}{l}\text { 2. Capacity of infrastructures to withstand extra pressure such } \\
\text { as floodwater }\end{array}$ & & 1.84 \\
\hline & & $\begin{array}{l}\text { 3. Integration of services such as transportation systems, } \\
\text { electric power and telephone }\end{array}$ & & 1.82 \\
\hline & & $\begin{array}{l}\text { 4. Shelter availability during emergencies such as schools and } \\
\text { stadiums }\end{array}$ & & 1.79 \\
\hline & & 5. Accessibility to critical infrastructure & & 1.78 \\
\hline & & 6. Management of waste created by natural hazards & & 1.74 \\
\hline & & $\begin{array}{l}\text { 7. Mobile resources for reconstruction including trained } \\
\text { workers }\end{array}$ & & 1.73 \\
\hline & & $\begin{array}{l}\text { 8. Location of built environment (probability of exposure to } \\
\text { hazards) }\end{array}$ & & 1.72 \\
\hline & & $\begin{array}{l}\text { 9. Monitoring of current built environment and existing } \\
\text { services A }\end{array}$ & & 1.68 \\
\hline & & $\begin{array}{l}\text { 10. Brown field treatment (contaminated land with low levels } \\
\text { of hazardous waste and pollutants) }\end{array}$ & & 1.4 \\
\hline & & Subtotal & N/A & 17.4 \\
\hline & \multirow{8}{*}{$\begin{array}{l}\text { 4. Eco- } \\
\text { nomic }\end{array}$} & 1. Funds available for reconstruction after disaster & & 2.67 \\
\hline & & 2. Access to financial services & & 2.35 \\
\hline & & 3. Level and diversity of economic resources & & 2.32 \\
\hline & & 4. Insurance coverage & & 2.27 \\
\hline & & 5. Home ownership status (homeowner/renter) & & 2.17 \\
\hline & & 6. Income and employment situation & & 2.17 \\
\hline & & 7. Size of Gross Domestic Product (GDP) per capita & & 1.94 \\
\hline & & Subtotal & N/A & 15.89 \\
\hline & \multirow{10}{*}{$\begin{array}{l}\text { 5. Informa- } \\
\text { tion and } \\
\text { commu- } \\
\text { nication }\end{array}$} & 1. Early warning system & & 1.81 \\
\hline & & 2. Reliability of communication systems & & 1.69 \\
\hline & & 3. Trusted sources of information & & 1.67 \\
\hline & & 4. Backup of critical data & & 1.62 \\
\hline & & 5. Responsibility of media & & 1.58 \\
\hline & & 6. Use of community platforms, e.g., mosques & & 1.54 \\
\hline & & 7. Visual alerting systems & & 1.5 \\
\hline & & 8. Ability to exploit social media & & 1.47 \\
\hline & & $\begin{array}{l}\text { 9. Ability to cascade information from international through } \\
\text { regional to local communities }\end{array}$ & & 1.42 \\
\hline & & Subtotal & N/A & 14.3 \\
\hline
\end{tabular}


Table 3 (Continued)

\begin{tabular}{|c|c|c|c|c|}
\hline $\begin{array}{l}\text { Frame- } \\
\text { work }\end{array}$ & Dimension & Indicator & $\begin{array}{l}\text { Num- } \\
\text { ber of } \\
\text { sub- } \\
\text { indi- } \\
\text { cator }\end{array}$ & $\begin{array}{l}\text { Weight } \\
(\%)\end{array}$ \\
\hline \multirow{36}{*}{$\mathrm{CCR} 2$} & \multirow[t]{12}{*}{ 6. Social } & 1. Risk awareness and training & & 1.02 \\
\hline & & 2. Risk perceptions & & 0.98 \\
\hline & & 3. Sense of community & & 0.97 \\
\hline & & 4. Personal faith and attitudes & & 0.96 \\
\hline & & 5. Trust in authorities & & 0.95 \\
\hline & & 6. Previous experience & & 0.94 \\
\hline & & 7. Social networks & & 0.91 \\
\hline & & 8. Faith organizations & & 0.88 \\
\hline & & 9. Education level & & 0.78 \\
\hline & & 10. Demography (age and gender) & & 0.77 \\
\hline & & 11. National language non-speaking (percentage) & & 0.74 \\
\hline & & Subtotal & N/A & 9.9 \\
\hline & \multirow{6}{*}{$\begin{array}{l}\text { 1. Socio- } \\
\text { economic }\end{array}$} & 1. Demography & 5 & \\
\hline & & 2. Livelihood & 5 & \\
\hline & & 3. Health & 5 & \\
\hline & & 4. Social capital & 5 & \\
\hline & & 5. Education and awareness & 5 & \\
\hline & & Subtotal & 25 & N/A \\
\hline & \multirow[t]{6}{*}{ 2. Physical } & 1. Transportation & 5 & \\
\hline & & 2. Residential infrastructure & 5 & \\
\hline & & 3. Electricity & 5 & \\
\hline & & 4. Telecommunication & 5 & \\
\hline & & 5. Water and sanitation & 5 & \\
\hline & & Subtotal & 25 & N/A \\
\hline & \multirow{6}{*}{$\begin{array}{l}\text { 3. Institu- } \\
\text { tional }\end{array}$} & 1. Laws and policy & 5 & \\
\hline & & 2. Coordination & 5 & \\
\hline & & 3. Emergency response & 5 & \\
\hline & & 4. Adaptive action & 5 & \\
\hline & & 5. Governance & 5 & \\
\hline & & Subtotal & 25 & N/A \\
\hline & \multirow{6}{*}{$\begin{array}{l}\text { 4. Coastal } \\
\text { zone } \\
\text { manage- } \\
\text { ment }\end{array}$} & 1. Embankment and shoreline & 5 & \\
\hline & & 2. Mangrove management & 5 & \\
\hline & & 3. Coastal biodiversity conservation & 5 & \\
\hline & & 4. Coastal pollution control & 5 & \\
\hline & & 5. Coastal land use & 5 & \\
\hline & & Subtotal & 25 & N/A \\
\hline
\end{tabular}


Table 3 (Continued)

\begin{tabular}{llll}
\hline $\begin{array}{l}\text { Frame- } \\
\text { work }\end{array}$ & Dimension & Indicator & $\begin{array}{l}\text { Num- Weight } \\
\text { ber of } \%) \\
\text { sub- } \\
\text { indi- } \\
\text { cator }\end{array}$ \\
\hline \multirow{2}{*}{$\begin{array}{c}\text { 5. Environ- } \\
\text { mental }\end{array}$} & 1. Frequency of natural disasters & 5 \\
& 2. Climate components & 5 \\
& 3. Geophysical components & 5 \\
& 4. Biogeochemical components & 5 & \\
& 5. Environmental safeguard measures & 5 & \\
& Subtotal & 25 & N/A \\
\hline
\end{tabular}

When essential public services are discontinued, this has a negative impact on any rescue and relief operations, which, in turn, can affect recovery. A lack of modern infrastructural facilities, including potable water, reliable public transportation, and electricity, all leave a community vulnerable in the aftermath of a disaster. Robust and dynamic public services are thus necessary for infrastructure resilience. The assessment indicators that fall under infrastructure resilience were all drawn from the nine frameworks that have been assessed. These include transportation, health, utilities, communication, embankment, and shoreline.

The study also considers the dimension of governance and institutional resilience. This can be described as the role that governments and associated institutions play in helping to build resilient communities. A proper understanding of governance must incorporate the roles and responsibilities of all levels of government (local, state, and federal), as well as the extent to which these either impede or facilitate community resilience. For example, farmers' groups, fishermen's groups, and faith-based organizations can also have a strong impact on communities. They can play a role in promoting disaster risk education and community-based support measures. With this in mind, the institutional indicators and variables were created based on an understanding of sociopolitical issues within the study area. The general aim of these variables is to measure the institutionalization of disaster risk reduction.

\subsubsection{Assessment indicators and sub-indicators}

In order to assess coastal community resilience, several methodological approaches have been adopted. Many of these assessment indicators have been used within a framework that aims to generate relevant, usable information that will increase the size of the current database, which draws information from a variety of sources (Cutter et al. 2014). Indicators can be described as parameters that help to explain the conditions or circumstances within a specific region that cannot be obtained directly. Indicators can also be used to assess the success and performance of these evaluation systems. They can also estimate qualitative data and assess quantitative data and are also suitable for application in a range of different contexts. This means that indicators can be referred to by various names (i.e., categories, indicators, and sub-indicators). Furthermore, indicators can cover a range of aspects, such as demographics, employment, livelihood, community awareness, land use, and warning and evacuation systems (DasGupta and Shaw 2015). 
Each chosen framework is made up of indicators that are associated with aspects that can be used to assess community resilience when coastal disasters occur. As Table 3 shows, these indicators generally consist of one or more sub-indicator (Alshehri et al. 2015) to illustrate their multifaceted nature. Community resilience indicators and sub-indicators can be associated with particular values or roles that enhance a community's resilience to a maritime disaster (Courtney et al. 2008). These can include infrastructure and public facilities, the accessibility of roads, education level, voluntary groups, marine pollution, and the frequency of natural hazards. There are two main categories of indicators: common indicators for all frameworks and specific indicators for particular countries or regions. Examples include mangrove management and sea rise level in CCR2, mean elevation of the area in RIM, and DRR strategies in IN-CDRI and LDRI.

\section{Results and discussion}

In ideal circumstances, the coastal community resilience frameworks should provide a holistic framework to incorporate multiple dimensions and aspects of resilience during the assessment process (Kafle 2012). The different dimensions of resilience addressed in each of the selected frameworks are given in Table 3. A thorough review of the criteria for each framework led to the identification of four common dimensions: society and economy, environment and climate change, infrastructure, and governance and institutions. Table 4 illustrates each dimension, split into indicators, which are then further divided into resilience sub-indicators.

However, all of the frameworks suffer from various shortcomings in terms of their design and implementation, as alluded to by Spellman and Whiting (2006). This study has identified two pertinent issues that need further deliberation, as provided in the following subsections.

\subsection{Disparities regarding the community resilience dimensions and indicators}

The metric can be described as applicable to the integration and assessment of the compatibility of the frameworks. Table 5 provides a detailed analysis of the selected frameworks and their magnitude of relevance or applicability within different dimensions and relative to specific indicators and sub-indicators. Superficially, it can be inferred that nearly all of the frameworks are incompatible or loosely integrated. For example, in the society and economy dimension, nearly all frameworks fail to capture vital factors that determine the capacity of a coastal community to overcome the effects of natural disasters to their ordinary lives. For example, under the 'demography' indicator, most frameworks loosely or fail to capture the population growth rate. For example, the CCR1 framework is 67\% inapplicable, $24 \%$ semi-applicable, and $10 \%$ applicable in the social and economic dimension.

It is important to assess the extent of the integration of the frameworks on an individual basis. Table 5 reveals that the CCR2 framework is the most broadly integrated across the four dimensions, accounting for $61 \%$ of fully applicable indicators, followed by CRDSA, which comprises $39 \%$ of the identified indicators that are fully applicable. It can be said that the CCR2's comprehensive coverage across all dimensions of this study is because of the fact that the framework is specifically designed for application to coastal hazards. 


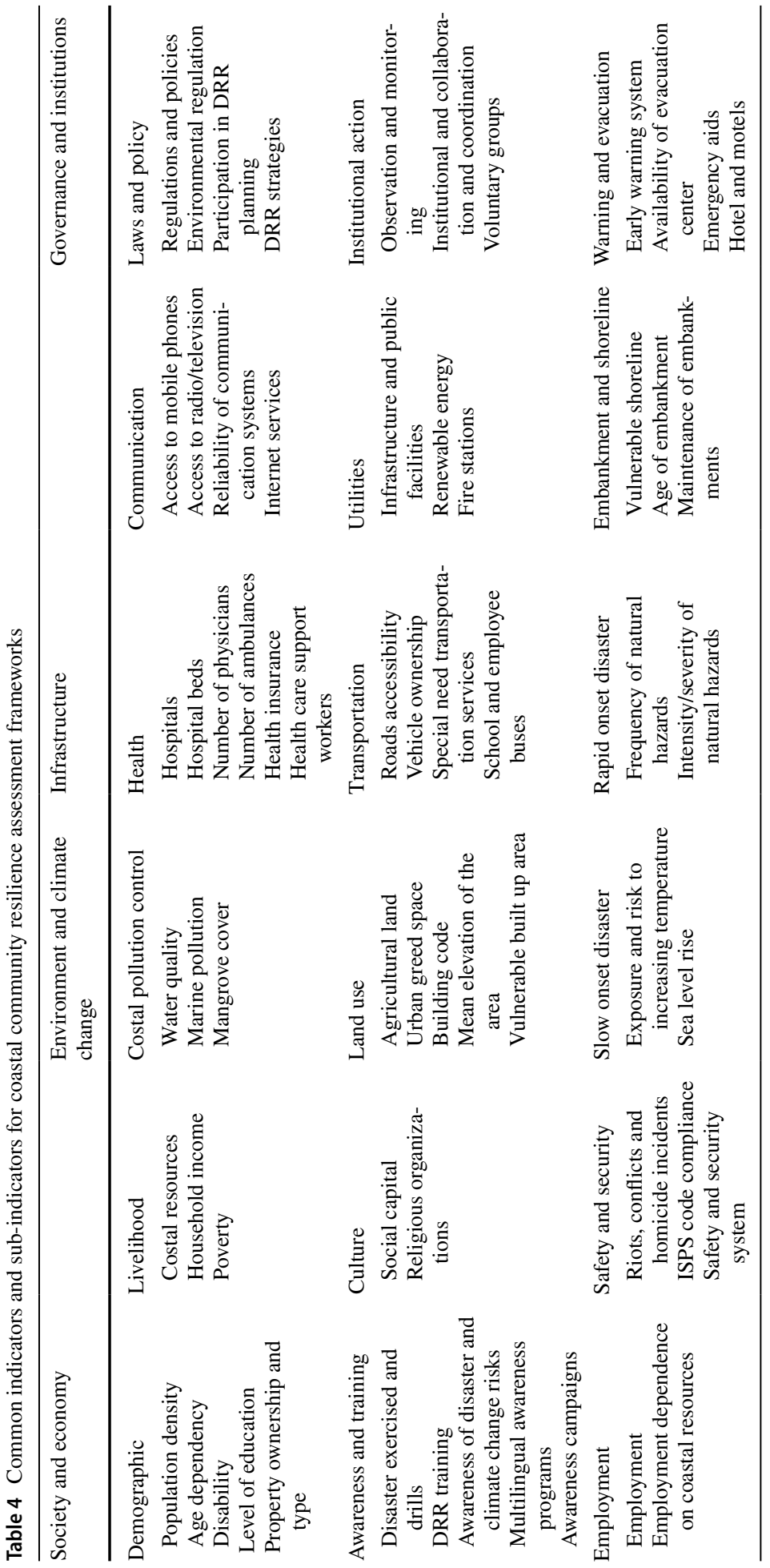




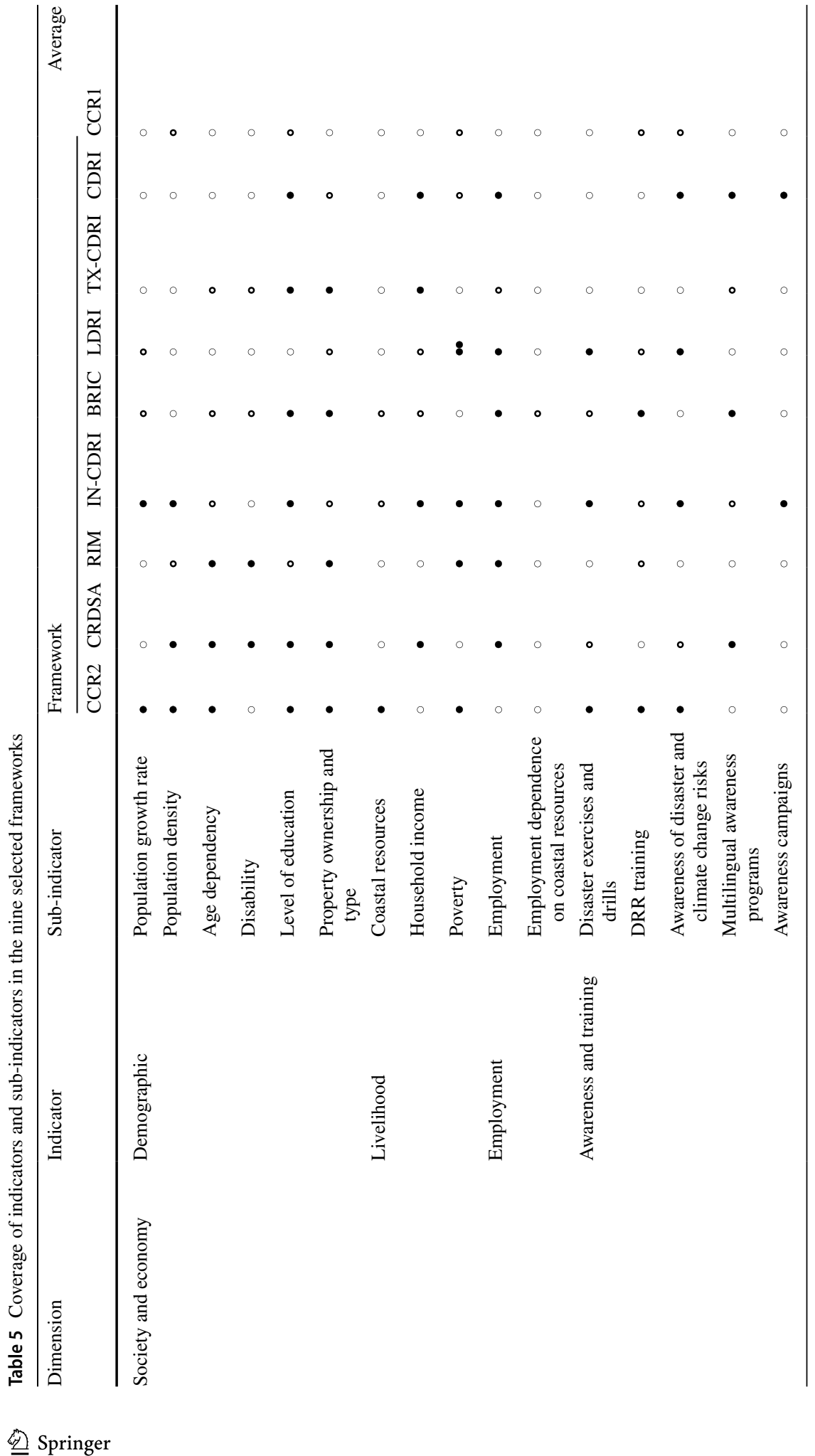




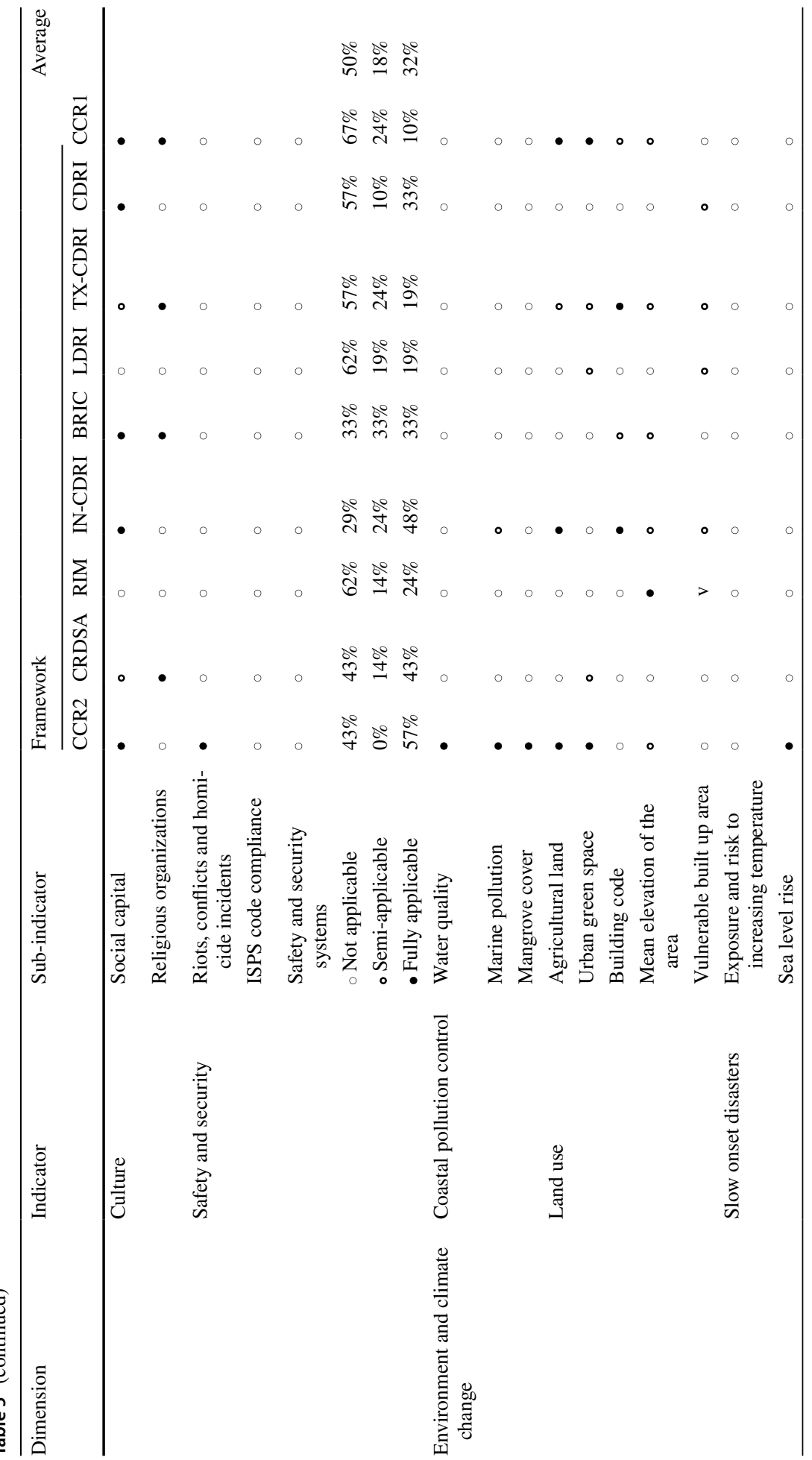




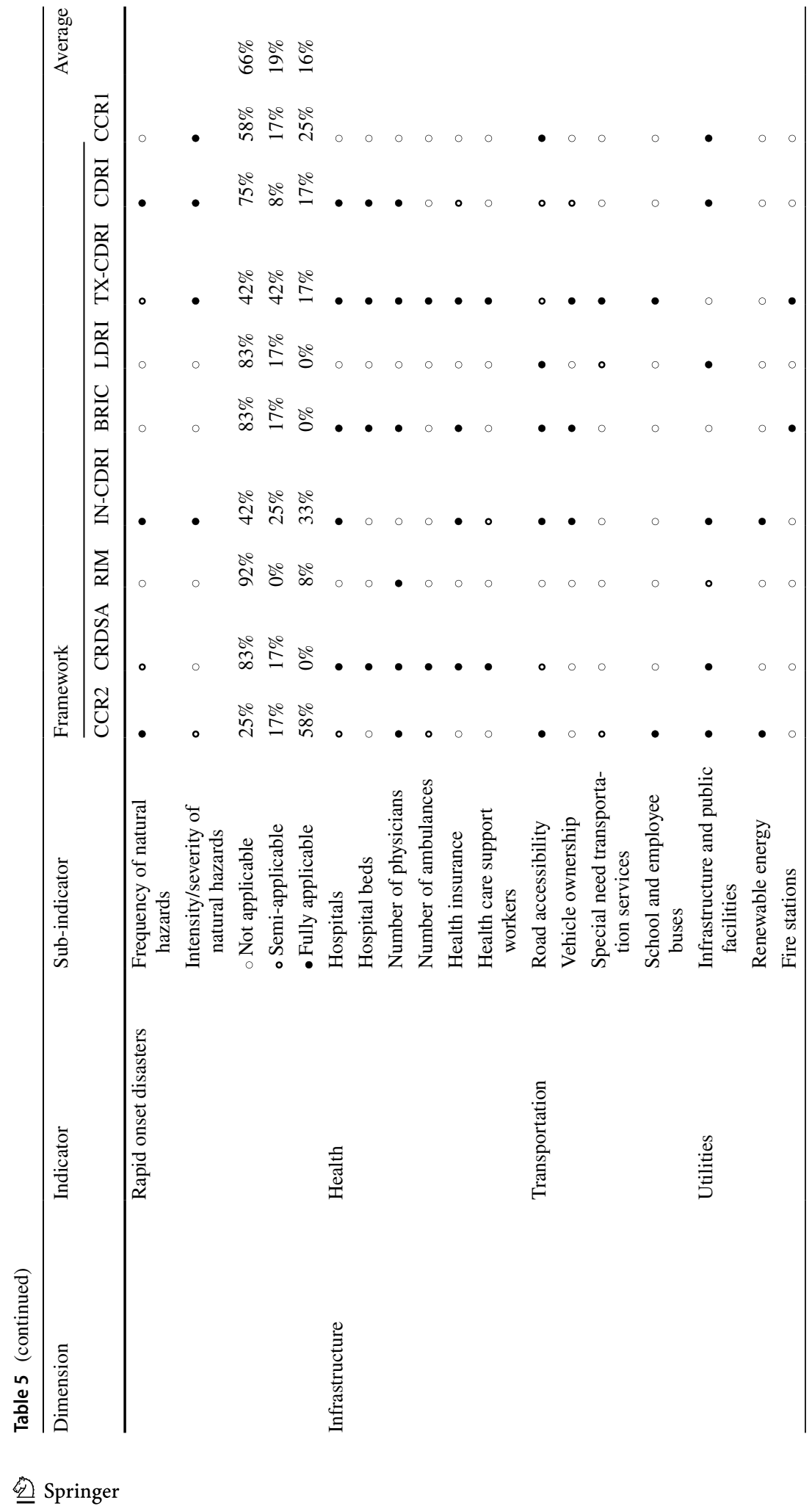




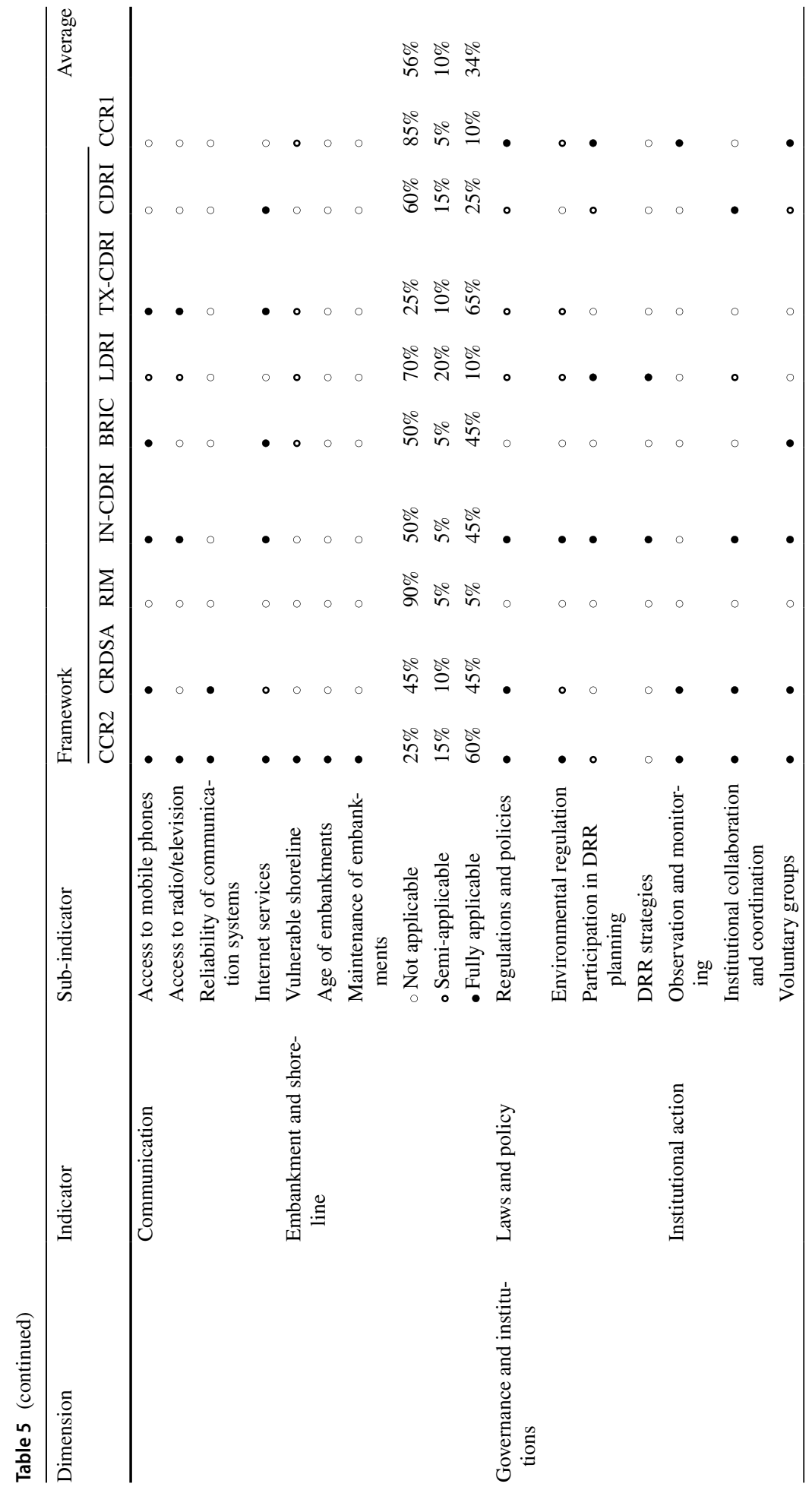




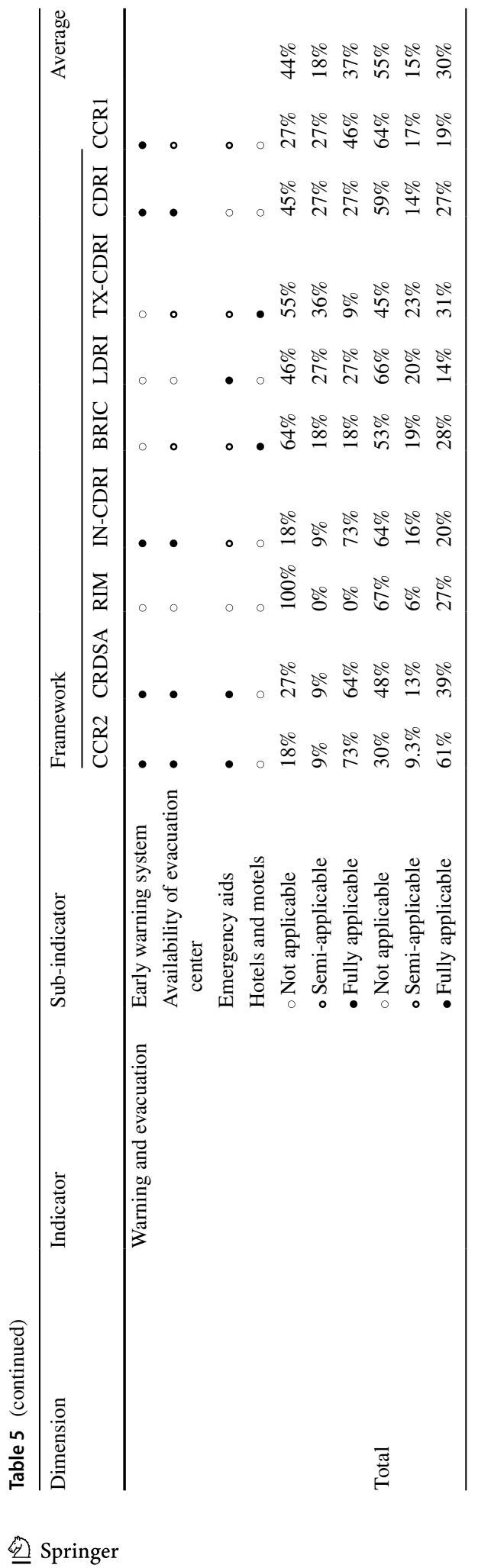


(a)

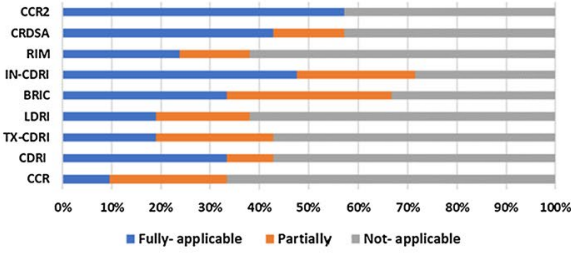

(b)

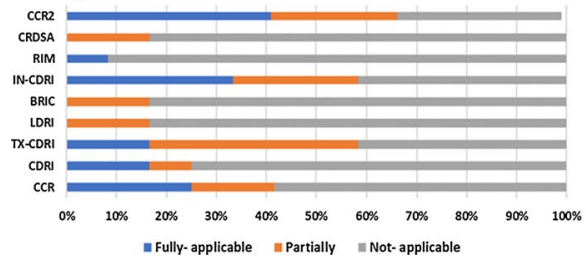

(c)

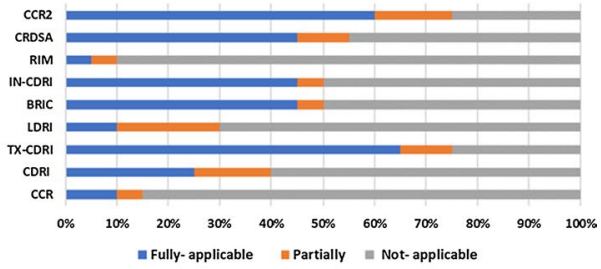

(d)

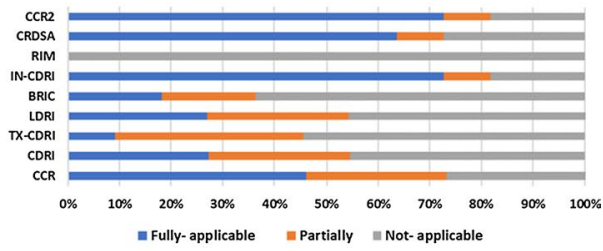

Fig. 2 Summary of the dimensional coverage in the nine selected frameworks. a Society and economy. b Environment and climate change. $\mathbf{c}$ Infrastructure and Institutions. d Governance and institutions

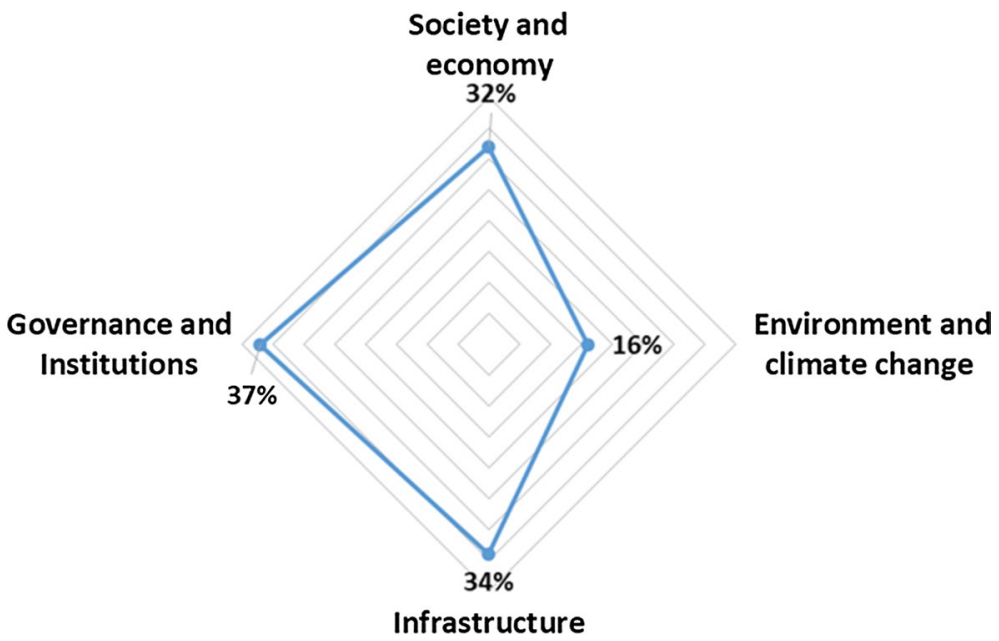

Fig. 3 Focus of the investigated coastal community resilience frameworks

However, this premise might not hold, given that CCR1, which was also designed specifically for this purpose, is highly incompatible with the dimensions included in this review. With the exception of the dimension of governance and institutions, the CCR1 framework appears to be less well integrated into the other dimensions, as shown by its high rate of irrelevance. Similarly, despite affording a specialist framework for coastal hazards, the RIM appears to be largely disconnected from the dimensions. In fact, it is wholly inapplicable in the governance and institutions dimension but, in the other dimensions, incompatible with the majority of the sub-indicators. 
It can thus be argued that the nine frameworks tend to concentrate more on governance and institutions and less on the environment and climate change. As such, the frameworks are highly compatible and well integrated into the legal policies surrounding the establishment of coastal community resilience interventions. This is the main reason why frameworks such as CCR2 and CRDSA exhibit impressive applicability indices in the dimension of governance and institutions. Conversely, there are few indicators in the environment and climate change dimension, which suggests that the environmental dimension is neglected within coastal community resilience interventions. However, it is essential to note that the CCR2 framework is highly effective in capturing the sub-indicators of the primary indicator, which is coastal pollution control.

From Figs. 2 and 3, it is evident that the selected frameworks place more emphasis on the government and institutions dimension (37\%), followed by the dimensions of infrastructure (34\%), society and economy (32\%), and environment and climate change (16\%), respectively. Their emphasis on government and institutions could suggest the omnipresence of external forces and factors that impede the efforts to enhance community resilience. In the ranking of the dimensions provided above, relatively less attention is paid to the environmental dimension, despite its significant role in informing and shaping community resilience. Orencio and Fujii (2013) suggest that a lack of regard for the environment when designing coastal community frameworks could stem from a lack of clarity concerning how environmental processes contribute to changes in climatic conditions. Matyas and Pelling (2015) note that research affords sufficient evidence to confirm that the presence of natural geographical assets, ecosystem protection, and resource management is vital for absorbing the shocks arising from natural disasters. Therefore, where community resilience is principally founded on environmental preservation, resilience tends to be formidable, and the likelihood of a speedy recovery is heightened. On the other hand, Sharifi (2016) observes that a failure to ensure the adequate integration of the environmental dimension increases the likelihood that coastal community resilience will be undermined.

Within the four dimensions of coastal community resilience, the 'society and economy' dimension's indicators include livelihood, demography, employment, culture, awareness and training, and safety and security. As mentioned previously, the evidence regarding the environment and climate change dimension is somewhat truncated. As such, it is mainly characterized by coastal pollution control, land use, slow onset disasters, and rapid onset disasters. In contrast, the infrastructure dimension is broad, encompassing a variety of indicators and sub-indicators. The chief indicators of the infrastructure dimension are health, utilities, transportation, communications, and embankments. Finally, the 'governance and institutions' dimension comprises laws and policy, institutional action, and warnings and evacuations as the principal indicators of coastal community resilience, as given in Table 4.

\subsection{Construction of the coastal community resilience frameworks}

\subsubsection{Participatory methods}

The frameworks were mainly developed by identifying an initial list of indicators following an extensive literature search, and by using stakeholders and experts' opinions and perceptions to achieve a consensus regarding the key indicators and assigning weights to each, in order to assess community resilience and the ability to cope with disasters. The majority of the frameworks employed a combination of both quantitative (i.e., numerical data) and qualitative (i.e., public opinions and expert judgments) methods (Alshehri et al. 2015). The 
mixed-methods approach of building a consensus around key indicators and sub-indicators can also be found in the literature on sustainability assessment frameworks (Ameen et al. 2015; Ameen and Mourshed 2018), which are similar in concept to the CCR frameworks reviewed in this study.

When various stakeholders are involved, the benefits of using participatory methods are numerous. As Table 6 indicates, 90\% of the chosen frameworks were developed using extensive literature reviews and experts' opinions. Only one framework (BRIC) depended solely on a literature review. Although community members possess a good knowledge of the needs, vulnerabilities, and coping capacities of their areas, very few assessment frameworks have been developed with reference to public opinion. Consequently, the local needs and conditions are frequently not reflected appropriately in these frameworks.

Sharifi (2016) claims that participatory methods can build capacity, improve the local understanding of resilience and risk, and establish a platform for sharing experiences and knowledge. They can also encourage collaborative design, and the development of techniques to enhance accuracy. Additionally, the assessment metric enables selected interventions to reflect the priorities of a community and thus improve local leadership, legitimacy, and decisions in terms of trade-offs (Cohen et al. 2016; Arbon et al. 2016).

After conducting the review, it emerged that there is currently no comprehensive method through which to develop a community resilience framework using both literature reviews and the perceptions of stakeholders and experts. Thus, there is an urgent need to develop a new framework utilizing a participatory methods approach.

\subsubsection{Risk identification}

It is pertinent to assess how each framework captured risk on a temporal scale. There appears to be a link between the extent to which various risks are considered and how well the frameworks integrate within the resilience-building programs. Communities are

Table 6 Methods and temporal scope of the nine selected frameworks

\begin{tabular}{|c|c|c|c|c|c|c|c|c|}
\hline \multirow[t]{2}{*}{ Framework } & \multicolumn{5}{|c|}{ Research method } & \multicolumn{3}{|c|}{ Temporal scope } \\
\hline & Overall $^{\mathrm{a}}$ & $\begin{array}{l}\text { Literature } \\
\text { review }\end{array}$ & $\begin{array}{l}\text { Public } \\
\text { opinion/per- } \\
\text { ception }\end{array}$ & $\begin{array}{l}\text { Expert } \\
\text { opinion/per- } \\
\text { ception }\end{array}$ & $\begin{array}{l}\text { Expert } \\
\text { consulta- } \\
\text { tion }\end{array}$ & Past & Current & Future \\
\hline CCR & Qualitative & $\sqrt{ }$ & $\sqrt{ }$ & & & $\sqrt{ }$ & $\sqrt{ }$ & $\sqrt{ }$ \\
\hline CDRI & Mixed & $\sqrt{ }$ & & $\sqrt{ }$ & & $\sqrt{ }$ & $\sqrt{ }$ & \\
\hline TX-CDRI & Mixed & $\sqrt{ }$ & & $\sqrt{ }$ & & $\sqrt{ }$ & $\sqrt{ }$ & \\
\hline LDRI & Mixed & $\sqrt{ }$ & & $\sqrt{ }$ & $\sqrt{ }$ & & $\sqrt{ }$ & \\
\hline BRIC & Quantitative & $\sqrt{ }$ & & & & & $\sqrt{ }$ & \\
\hline IN-CDRI & Mixed & $\sqrt{ }$ & & $\sqrt{ }$ & & & $\sqrt{ }$ & $\sqrt{ }$ \\
\hline RIM & Mixed & $\sqrt{ }$ & & $\sqrt{ }$ & & $\sqrt{ }$ & $\sqrt{ }$ & \\
\hline CRDSA & Mixed & $\sqrt{ }$ & $\sqrt{ }$ & $\sqrt{ }$ & $\sqrt{ }$ & & $\sqrt{ }$ & \\
\hline CCR2 & Mixed & $\sqrt{ }$ & $\sqrt{ }$ & & & & $\sqrt{ }$ & \\
\hline Count & & 9 & 3 & 6 & 2 & 4 & 9 & 2 \\
\hline Percentage & & $100 \%$ & $33 \%$ & $67 \%$ & $22 \%$ & $44 \%$ & $100 \%$ & $22 \%$ \\
\hline
\end{tabular}

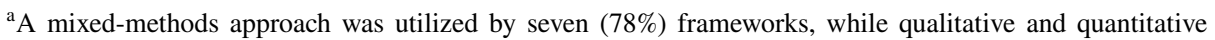
methods were utilized by one $(11 \%)$ framework each 
spatially delineated, which may explain why the consideration of geospatial risks is more pronounced in the coastal community resilience frameworks. According to Norris et al. (2008), community resilience comprises four sets of adaptive capacities-social capital, economic development, community competence, and information and communication that together determine the disaster readiness of the community. However, the authors acknowledge the uncertainties that may be experienced during the implementation stages and stress on the flexibility of the resilience plan so that effective decisions can be made. One of the ways uncertainties can be reduced is by linking the past experiences of hazards, adaptation, and mitigation with the present and the future. The temporal scope of a framework is, therefore, an important component of resilience and should ideally be linked with the spatial scope of an assessment framework.

We evaluated the resilience of a community in a time-based continuum to assess how each phase is connected with the previous phases and succeeds with other phases, i.e., their temporal scope. Table 6 reveals that only $45 \%$ of the frameworks focus on the present conditions, while $35 \%$ consider the past, and $20 \%$ examine both the present and future. If the frameworks only encompass the past and present, they risk ignoring the changing climatic conditions. Therefore, it is evident that the frameworks must consider the past, present, and future if they are to understand the system dynamics more effectively and develop strategies for coping with potential changes in the future.

Collier et al. (2016) believe that coastal community resilience should be evaluated on a time-based continuum to guarantee that risk is captured at all times. Sharifi (2016) supports this point, arguing that all stages are linked to events that take place before or after any assessment. This may explain why risk is poorly integrated into the dimensions. Of the current frameworks, CCR2 and CRDSA offer good examples of risk capture because they consider both present and future conditions. Sharifi (2016), Cimellaro et al. (2016) and Arbon et al. (2016) all believe that monitoring changes along a time-based continuum differentiate the assessment of resilience from evaluations of vulnerability. The assessment of resilience considers the past and future, while evaluations of vulnerability focus solely on the present.

\section{Conclusion}

Resilience is an important goal when preparing coastal communities for natural and human-made disasters, a fact that is compounded by the increasing exposure of populations to these hazards. Community resilience to disasters is essential if an affected community is to be able to rebuild itself to pre-disaster levels. In this respect, it is essential to enhance community resilience by identifying beneficial criteria that will make this possible. In this study, nine selected frameworks were critically analyzed, and different resilience dimensions addressed in each of the selected frameworks presented. Four common dimensions were identified based on a thorough review of the criteria of each framework. These dimensions are-society and economy, environment and climate change, infrastructure, and governance and institutions. These were then divided into eighteen indicators, as well as a total of sixty-four sub-indicators.

Comparison matrices were developed with the intention of assessing the extent of the applicability of the different frameworks across several sub-indicators within four dimensions. The review found that most of the frameworks address multiple aspects of resilience and so were significantly broad in scope. Additionally, it emerged that despite the fact that 
several of the frameworks were designed specifically for coastal areas, these were mostly incompatible and consequently poorly integrated into resilience programs. In addition, many of the frameworks employed a narrower scope when dealing with the environment and climate change dimension when contrasted with that for the other dimensions. In this review, it was confirmed that ecosystem protection and resource management are vital for absorbing the shocks resulting from natural disasters. Therefore, where environmental preservation is the principal foundation of community resilience, then resilience is formidable, and the likelihood of a speedy recovery from disaster is heightened.

The frameworks have also been assessed according to how well the identified indicators and sub-indicators represent the needs of the community. It can be inferred that together, the reviewed frameworks addressed the bulk of the reported issues related to coastal community resilience. However, there exists a significant mismatch between the frameworks in their coverage and focus. The variations in coverage and focus result from the varying needs of the community considering which the respective framework was developed. Local relevance is thus important for the design, development, and implementation of any framework as they are not readily transferable from one location or region to the other. Experts and stakeholders should, therefore, be consulted to identify the relevance and extent of each resilience indicator to local standards and practices to ensure that the frameworks remain sufficiently objective.

Open Access This article is licensed under a Creative Commons Attribution 4.0 International License, which permits use, sharing, adaptation, distribution and reproduction in any medium or format, as long as you give appropriate credit to the original author(s) and the source, provide a link to the Creative Commons licence, and indicate if changes were made. The images or other third party material in this article are included in the article's Creative Commons licence, unless indicated otherwise in a credit line to the material. If material is not included in the article's Creative Commons licence and your intended use is not permitted by statutory regulation or exceeds the permitted use, you will need to obtain permission directly from the copyright holder. To view a copy of this licence, visit http://creativecommons.org/licenses/by/4.0/.

\section{References}

Ainuddin S, Routray JK (2012) Community resilience framework for an earthquake prone area in Baluchistan. Int J Disaster Risk Reduct 2:25-36

Alshehri SA, Rezgui Y, Li H (2015) Disaster community resilience assessment method: a consensus-based Delphi and AHP approach. Nat Hazards 78:395-416

Ameen RFM, Mourshed M (2018) Urban sustainability assessment framework development: the ranking and weighting of sustainability indicators using analytic hierarchy process. Sustain Cities Soc 44:356-366

Ameen RFM, Mourshed M, Li H (2015) A critical review of environmental assessment tools for sustainable urban design. Environ Impact Assess Rev 55:110-125

Arbon P (2014) Developing a model and tool to measure community disaster resilience. Aust J Emerg Manag 29(4):12-16

Arbon P, Steenkamp M, Cornell V, Cusack L, Gebbie K (2016) Measuring disaster resilience in communities and households: pragmatic tools developed in Australia. Int J Disaster Resil Built Environ 7:201-215

Bealt J, Mansouri SA (2018) From disaster to development: a systematic review of community-driven humanitarian logistics. Disasters 42(1):124-148

Burton CG (2015) A validation of metrics for community resilience to natural hazards and disasters using the recovery from Hurricane Katrina as a case study. Ann As Am Geogr 105:67-86

Chandra A, Acosta JD, Howard S, Uscher-Pines L, Williams MV, Yeung D, Garnett J, Meredith LS (2011) Building community resilience to disasters: a way forward to enhance national health security. RAND Corporation, Santa Monica. ISBN 978-0-8330-5195-0

Chelleri L, Waters JJ, Olazabal M, Minucci G (2015) Resilience trade-offs: addressing multiple scales and temporal aspects of urban resilience. Environ Urban 27:181-198

Cimellaro GP, Renschler C, Reinhorn AM, Arendt L (2016) PEOPLES: a framework for evaluating resilience. J Struct Eng 142:04016063 
Cohen O, Bolotin A, Lahad M, Goldberg A, Aharonson-Daniel L (2016) Increasing sensitivity of results by using quantile regression analysis for exploring community resilience. Ecol Ind 66:497-502

Collier MJ, Nedovic-Budic Z, Aerts J, Connop S, Foley D, Foley K, Newport D, McQuaid S, Slaev A, Verburg P (2013) Transitioning toresilience and sustainability in urban communities. Cities 32:S21-S28

Cooper R, Boyko C (2010) How to design a city in five easy steps: exploring VivCity 2020's process and tools for urban design decision making? J Urban 3(3):253-273

Courtney CA, Ahmed AK, Jackson R, McKinnie D, Rubinoff P, Stein A, Tighe S, White A (2008) Coastal Community Resilience in the Indian ocean region: a unifying framework, assessment, and lessons learned. In: Solutions to coastal disasters congress, pp 990-1001

Cutter SL (2016) The landscape of disaster resilience indicators in the USA. Nat Hazards 80:741-758

Cutter SL, Ash KD, Emrich CT (2014) The geographies of community disaster resilience. Glob Environ Change 29:65-77

DasGupta R, Shaw R (2015) An indicator based approach to assess coastal communities' resilience against climate related disasters in Indian Sundarbans. J Coast Conserv 19:85-101

Dolin J, Black P, Harlen W, Tiberghien A (2017) Exploring relations between formative and summative assessment. In: Dolin J, Evans R (eds) Transforming assessment. Contributions from Science Education Research, vol 4, pp 53-80

Ewing L, Synolakis C (2011) Coastal resilience: Can we get beyond planning the last disaster? Solut Coast Disasters 2011:936-947

Joerin J, Shaw R, Takeuchi Y, Krishnamurthy R (2014) The adoption of a climate disaster resilience index in Chennai, India. Disasters 38:540-561

Kafle SK (2012) Measuring disaster-resilient communities: a case study of coastal communities in Indonesia. J Bus Contin Emerg Plan 5:316-326

Lam NSN, Reams M, Li K, Li C, Mata LP (2016) Measuring community resilience to coastal hazards along the Northern Gulf of Mexico. Nat Hazards Rev 17(1):04015013

Larkin S, Fox-Lent C, Eisenberg DA, Trump BD, Wallace S, Chadderton C, Linkov I (2015) Benchmarking agency and organizational practices in resilience decision making. Environ Syst Decis 35:185-195

Lloyd MG, Peel D, Duck RW (2013) Towards a social-ecological resilience framework for coastal planning. Land Use Policy 30:925-933

Matyas D, Pelling M (2015) Positioning resilience for 2015: the role of resistance, incremental adjustment and transformation in disaster risk management policy. Disasters 39(S1):S1-S18

McDaniels T, Chang S, Cole D, Mikawoz J, Longstaff H (2008) Fostering resilience to extreme events within infrastructure systems: characterizing decision contexts for mitigation and adaption. Glob Environ Change 18:310-318

Meerow S, Newell JP, Stults M (2016) Defining urban resilience: a review. Landsc Urban Plan 147:38-49

Norris FH, Stevens SP, Pfefferbaum B, Wyche KF, Pfefferbaum RL (2008) Community resilience as a metaphor, theory, set of capacities, and strategy for disaster readiness. Am J Commun Psychol 41:127-150

Orencio PM, Fujii M (2013) A localized disaster-resilience index to assess coastal communities based on an analytic hierarchy process (AHP). Int J Disaster Risk Reduct 3:62-75. https://doi.org/10.1016/j.ijdrr .2012.11.006

Peacock WG, Merrell AV, Zahran S, Harriss RC, Stickney RR (2010) Advancing the resilience of coastal localities: developing, implementing and sustaining the use of coastal resilience indicators. A final report. Hazard reduction and recovery center. Final report for NOAA CSC Grant No. NA07NOS4730147

Sharifi A (2016) A critical review of selected tools for assessing community resilience. Ecol Ind 69:629-647

Sharifi A, Yamagata Y (2016) On the suitability of assessment tools for guiding communities towards disaster resilience. Int J Disaster Risk Reduct 18:115-124

Shaw R, Team I (2009) Climate disaster resilience: focus on coastal urban cities in Asia. Asian J Environ Disaster Manag 1:101-116

Spellman FR, Whiting NE (2006) Environmental science and technology: concepts and applications. Government Institutes, Rockville

Young JM, Solomon MJ (2009) How to critically appraise an article. Nat Rev Gastroenterol Hepatol 6(2):82-91

Publisher's Note Springer Nature remains neutral with regard to jurisdictional claims in published maps and institutional affiliations. 